\title{
RADIO ACCESS EVALUATION OF CELLULAR NETWORK IN AKURE METROPOLIS, NIGERIA
}

\author{
0. J. Mebawondu', F. M. Dahunsi ${ }^{2,}$, S. O. Adewale ${ }^{3}$ and B. K. Alese ${ }^{4}$ \\ 1,3,4, SCHOOL OF COMPUTING, FEDERAL UniverSity OF TECHNOLOGY, AKURE, ONDO STATE. NIGERIA \\ 2. Dept. of Electrical \& Electronics Engr' G, Federal Univ. of TeChnology, AKURE, Ondo STATE. NigERIA \\ Email addresses: ${ }^{1}$ mebawondu1010@gmail.com, ${ }^{2}$ fmdahunsi@gmail.com, ${ }^{3}$ adewale@futa.edu.ng, \\ 4 bkalese@futa.edu.ng
}

\begin{abstract}
The higher subscription, relative importance of voice calls, client's complaints and economy depression that now make clients to get value for money paid and need for more revenue by mobile network operator (MNOs) justified this work. The objective of this work is to measure, analyse, evaluate the performance of MNOs, and to recommend ways to improving their quality of service (QoS). Drive test approach was used for the measurements and statistical methods for the analysis. Results of the analysis shows that the quality of Voice service offered by MNOs is not optimal and there is room for improved quality service. Based on the key performance indicators, the mobile operators did not perform up to expectation. There are differences in the quality of voice service offered across mobile network operator networks based on the time of the day and the area under consideration. MNO1, MNO2, MNO3 and MNO4 gave varying quality of service. MNO4 had absolutely no dropped calls and performed best and consistently gave a retainability ratio above the target. MNO1 performance metrics were below the key performance indicator thresholds given by the Nigerian Communication Commission.
\end{abstract}

Keywords: Performance Evaluation, Quality of Service, Voice Services, Mobile Communication

\section{INTRODUCTION}

A very good platform for social, economic, political and other forms of communication is provided in telecommunication and in the Nigerian setting: mobile communication. It enhances business activities, government activities and has changed how people live, work, play and learn. The impact and coverage of mobile communication in Nigeria is particularly evident in Figure 1, which shows that the total number of active mobile subscribers is almost equivalent to the total number of active lines. This implies that more than $98 \%$ of active subscribers use mobile lines. The other lines which constitute the remaining $2 \%$ of active lines are Code Division Multiple Access (CDMA) lines, Voice over IP (VoIP) lines and fixed wireless/wired lines [1]

The market share among mobile network operators (MNOs) and total number of subscribers has increased rapidly over the past decade; as at December 2005 there were just 19,519,154 subscribers, by December 2016 there were $154,529,780$ subscribers. This is equivalent to an average increase of $12,273,693$ subscribers every year, by March 2017; there were 152,467,198 subscribers [1] and four mobile network operators. MTN remained the largest provider, and accounted for $36 \%$ of subscriber base, Airtel, Globalcom and others have $22.80 \%, 24.56 \%$ and $12.91 \%$ subscribers' base respectively. Teledensity grew from $16.27 \%$ in 2010 to $103.61 \%$ for the year 2017 [1].

Mobile communication is also a major source of Gross Domestic Product (GDP) for the country. Figure 2 shows Teledensity growth curve of Nigeria in relation to the GDP contribution by the telecommunication industry. GDP data in the telecommunication sector for the year 2004 -2009 was unavailable from. Data for years 2010 to 2017 (which is in presented in Figure 2) show that the telecommunication industry is a major player in the country's economy [1].

The telecommunication sector experiences various challenges despite numerous applications and advantages of mobile telephony. 


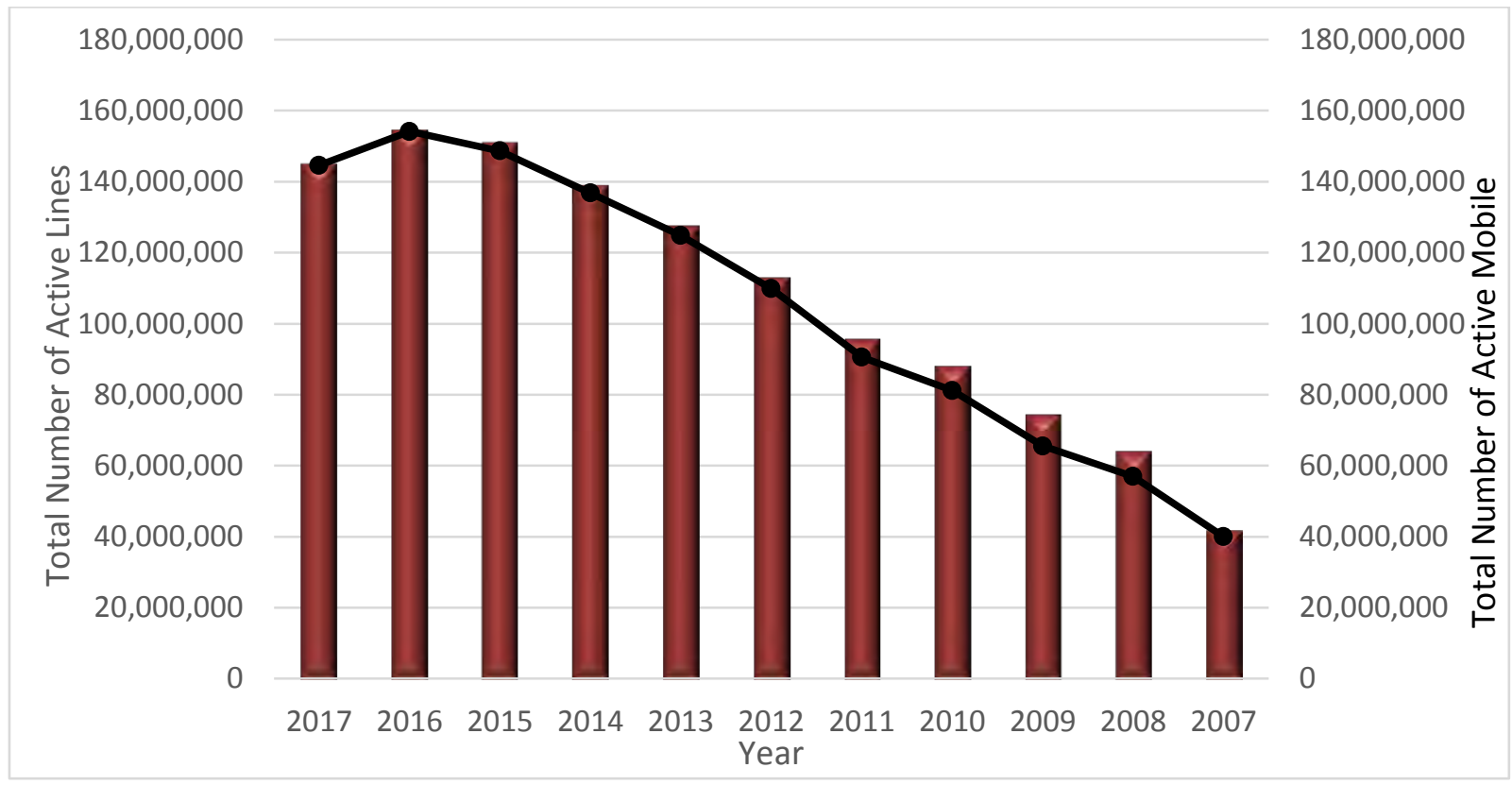

Figure 1: Total Number of Active Lines versus the Total Number of Active Mobile cellular Lines

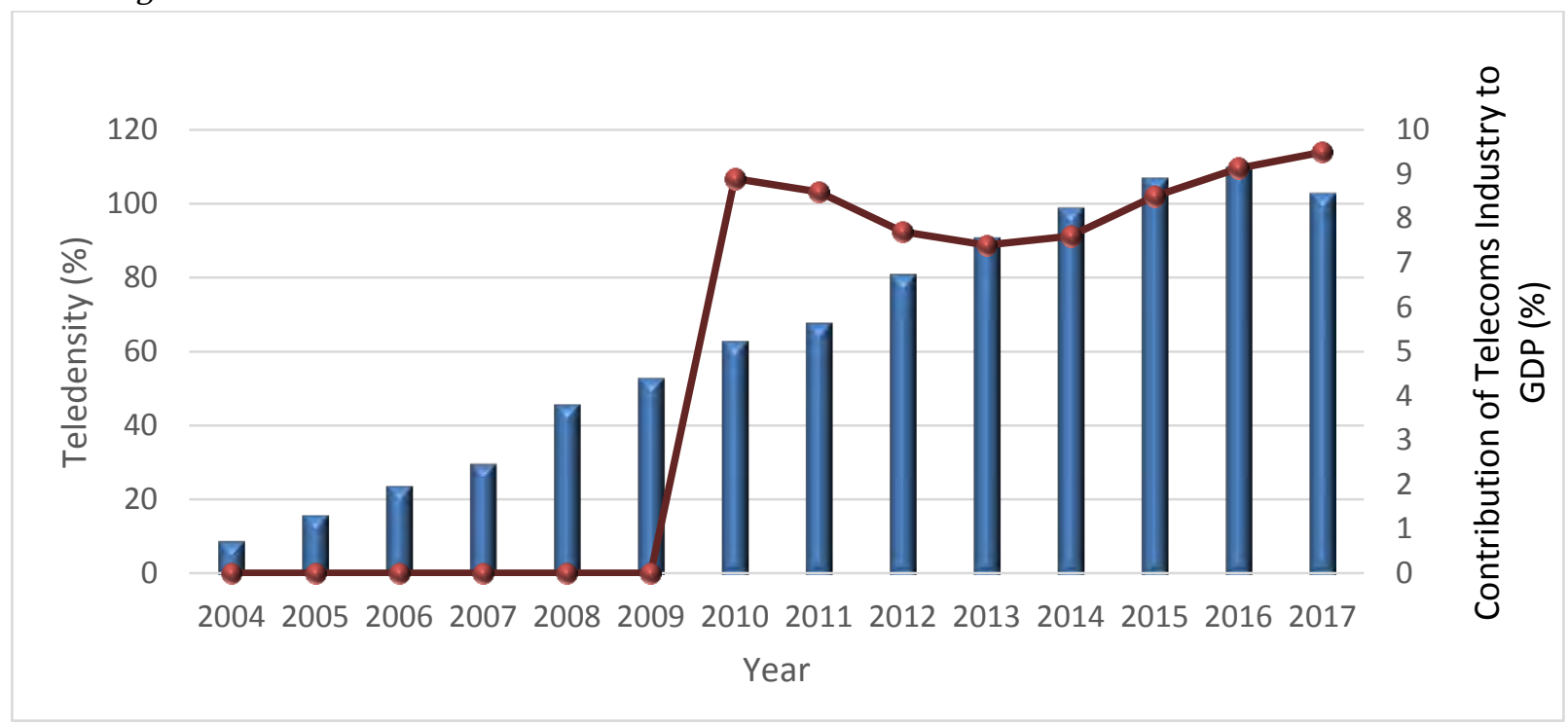

Figure 2: Teledensity Data and Contribution of the Telecommunication Industry to GDP

Some of the problems are subscriber's complaints due to low quality of service offered by the mobile network operators (MNO), requesting for valued service for money, etc. Mobile Network Operator's challenges includes irregular power supply for the Base Transceiver Station (BTS), use of expensive to manage and maintain generators, necessity to work alone sometimes instead of co-location sites, etc $[8,11]$.Based on the strength of subscriber complaint, MNO challenges and regulatory concerns, there is a need to measure, evaluate and optimize the quality of service of cellular network provided at every part of Nigeria. Measurements and evaluation of the voice calls in Nigeria is currently virtually dependent on data from network operators or their supervisory body $[1,2]$.
Hence, it is important to have another evaluation carried out by a third party to investigate the state of the network.

In mobile cellular networks, there are two important services made available by MNOs in the sector: data and voice services. As at December 2017, there are about 145 million active lines for voice services and 98 million subscriptions for data services [1]. This makes voice services very important having the widest coverage and deepest penetration, though there has been an appreciable increase in data services too as shown in Figure 3. Priority is therefore given to voice services as they are also considered the primary service. 


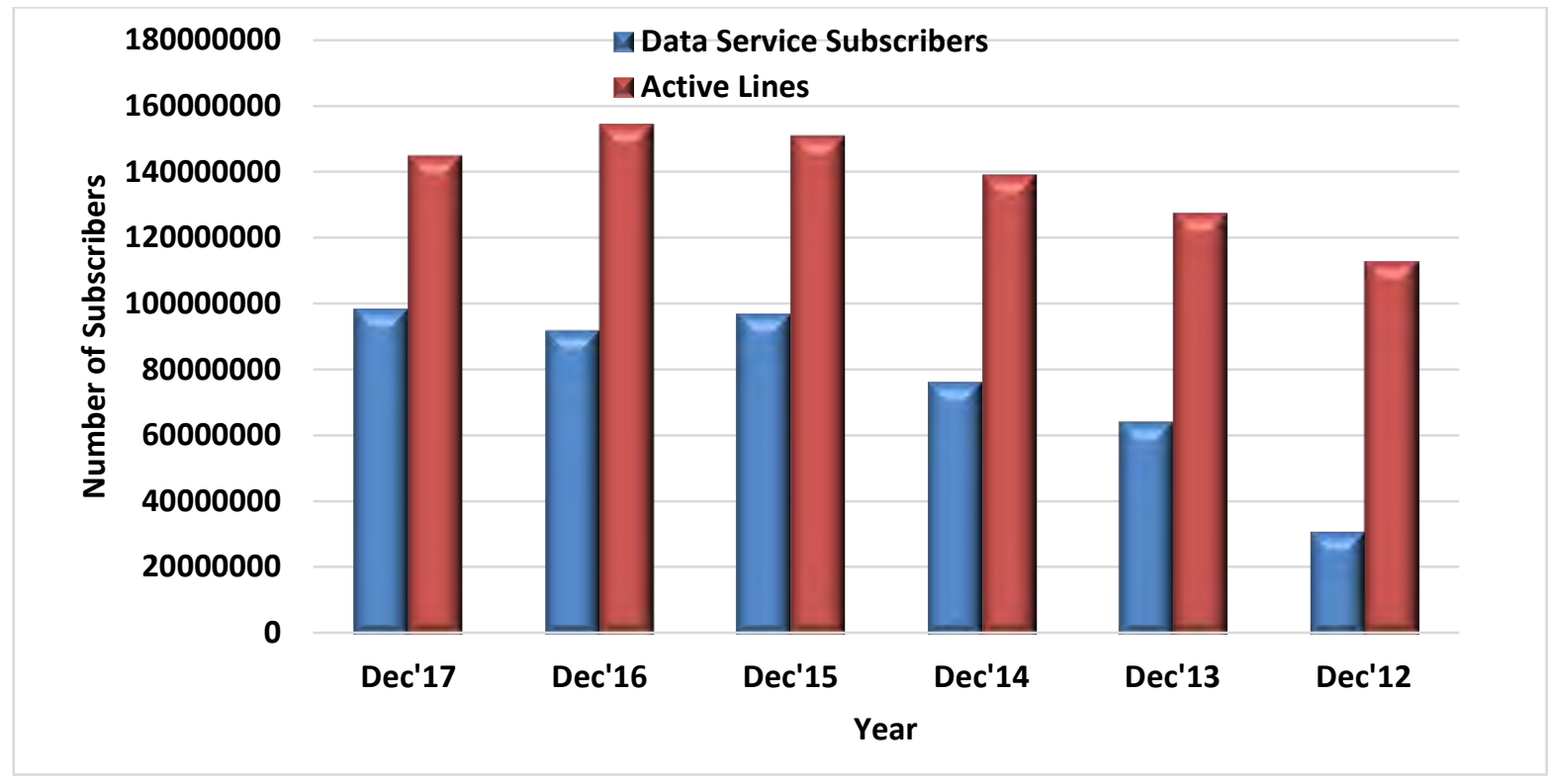

Figure 3: Number of Active Lines and Data Service Subscribers

There are two important parties involved in voice services: the calling and the receiving clients. At one end the caller initiates the call, at the other end, the receiver answers the call.

Based on the premise establishing the importance of voice services, this paper investigates the quality of service offered in Akure the capital city of Ondo State. Akure is mainly a civil servant and an agro-based state and therefore does not generate as much Average Revenue per User (ARPU) compared to Lagos, Port Harcourt, Kano and Abuja which are the business hubs of the Country. Mobile network operators tend to roll out better services at the aforementioned business hubs of the country.

Quality of Service (QoS) in telecommunication is the measure of quality of telecommunications services delivery based on some standard metrics. The measurement of QoS must be based on measures that can be readily interpreted by stakeholders to get realistic result and infer accurate information. Measurement of QoS of radio access quality must begin with a consideration for the users of that service and since it has to be carried out often, it must be cost effective.

There are four major techniques for measuring QoS parameters relating to voice services offered in mobile communication. The techniques include: questionnaire, drive test, network management system (NMS) and crowdsourcing [3-6].

Drive test methods were used by [4] and Emeruma [7]. Oseni, et al., [4] investigated radio frequency optimization of mobile networks in Abeokuta, Nigeria for improved quality of service. Drive test method used to collect data and post-processing software tool as used to analyze collected data. Poor coverage and degradation in QoS was attributed to the land's topology and physical obstruction.

Ozoveh and Usman [8] and Emeruma [7] also used drive-test technique for performance evaluation. Emeruma [7] presented a comparative analysis of signal strength of some cellular network in Umuahia, eastern Nigeria. Data was collected using the drive test technique and regression analysis and line graph were used for the comparative analysis. Ozoveh and Usman [8] analyzed the performance of Global System for Mobile communication (GSM) networks using drivetest method in Minna metropolis, Nigeria. They concluded that the network will operate more optimally if researchers were given unfiltered access to the mobile operator's database thereby allowing them to proffer well- suited solutions to the tele traffic engineering challenges particularly relating to mobile communication within the country.

Kyriazakos et al. [9], did a comprehensive study and performance evaluation of the operations of GSM and General Packet Radio Service (GPRS) system under varying traffic condition. Network management system (NMS) tool was used for data collection.

Adegoke et al., [10], Popoola et al., [6] presented QoS analysis of voice services and collection of performance metrics data was carried out using questionnaire/survey method. Their work identified and investigated three QoS parameters (factors) namely accessibility, retainability and voice service quality. They also appraised the performance of GSM in Nigeria and methods of improving them. Some of the 
identified problems are instability in power supply, security of infrastructure, inter-network connectivity. Other challenges are network congestion, call setup failure and call retention / call drop. The investigations by Adegoke et al. [10] covered 14 states in the federation while the paper by Popoola et al. [6] covered the whole country (Nigeria). Popoola et al. [11] provided comprehensive data on KPI parameters based on data collected from NCC, the data spans two years. The limitation of this research work is firstly; secondary data was used and detailed information from user's perspective in Akure city was not available. In the light of the research gap highlighted from the reviews and other issues such as increased subscribers, importance of voice calls, client's complaints, need for clients to get value for money and improved revenue for mobile network operators (MNOs) justifies the importance and need for this paper. The objective of this work is to measure and evaluate the quality of voice service offered by MNOs in Akure metropolis.

Benchmarking is a technique applied in telecommunication to accurately measure mobile network operator's (MNO) performance against the standards, presented in Table 1. It assists in analyzing the performance of MNOs and information acquired can be used to check and improve network performance. The research paper analyzed the key performance indicators (KPIs) and RSCP data collected using test drive collection method to carry out an objective evaluation of the QoS offered by network operators in Akure. This work is divided into five sections, section one, two and three are the overview, materials and methods and evaluation criteria respectively. Section four presents and discusses the results and section five concludes the paper.

\section{MATERIALS AND METHODS}

Drive test technique was employed to collect the required data for this research work. Drive test is the process of collecting mobile network traffic data from the cellular network in order to know or have an idea of the subscribers' perception of the network from the view of a single subscriber It was carried out to check the network performance by means of coverage evaluation, system availability, network capacity, network retainability and call quality. The materials used are drive test equipment: Laptop, TEMS phones, USB Cables, GPS and Car inverter and software. The software used are TEMS Investigation and Data Collection and MapInfo ${ }^{\circledR}$. The time of day analysis was also investigated to check if the timing of service affects the quality. Comparative analysis was also carried out across the mobile network operators available in the region of interest.

Summary of the collected data for the three test areas for morning, afternoon and evening (8am - 11am, 12 noon $-3 \mathrm{pm}$ and $4 \mathrm{pm}-7$ respectively) are shown in the appendix. Only the soft handover details were covered.

\section{EVALUATION CRITERIA}

To accurately measure the MNO's performance, the key performance indicators (KPIs) as specified by NCC (NCC, 2018). The KPIs' and their benchmark for good quality of service are given in Table 1 . The call drop rate (CDR) is the proportion of the calls that were cut off before the speaking parties had finished their conversation and before one of them had hung up. Traffic channel congestion rate (TCHCR) is failure in connecting to the service needed by the user after an SDCCH has been assigned. The received signal code power is also an important parameter which was measured. It gives an estimate of the power level the pilot channel of a cell is received and usually expressed in $\mathrm{dBm}$. With this parameter, different cells using the same carrier can be compared and handover or cell selection decision can be taken.

Table 1: The KPIs, their definitions and set threshold (Source: [1, 13])

\begin{tabular}{|c|c|c|c|c|}
\hline $\mathrm{S} / \mathrm{N}$ & Key Performance Indicator & Accronym & Definitions & Target (\%) \\
\hline 1 & Call Setup Success Rate & CSSR & $\begin{array}{l}\text { Number of the unblocked call attempts divided by } \\
\text { the total number of call attempts. Or (1 - Blocking } \\
\text { Probability) } \times 100 \%\end{array}$ & $\geq 98 \%$ \\
\hline 2 & $\begin{array}{l}\text { Traffic Channel Congestion } \\
\text { (with and without Handover) }\end{array}$ & TCH Cong & $\begin{array}{l}\text { Is the ratio of the number of unsuccessful TCH } \\
\text { requests to the total number of TCH request } \\
\text { attempts expressed as percentage }\end{array}$ & $\begin{array}{l}\leq 2 \% \mathrm{WOH} \\
\leq 4 \% \mathrm{WHO}\end{array}$ \\
\hline 3 & Call Drop Rate & CDR & $\begin{array}{l}\text { CDR Is the number of dropped calls divided by the } \\
\text { total number of call attempts Or ( } 1 \text { - Call } \\
\text { Completion Ratio) } \times 100 \%\end{array}$ & $\leq 2 \%$ \\
\hline 4 & $\begin{array}{l}\text { Standalone Dedicated Control } \\
\text { Channel Congestion }\end{array}$ & SDCCH CONG & $\begin{array}{l}\text { Is a logical signalling channel that is used for call } \\
\text { set-up. Once a call is successfully setup SDCCH is } \\
\text { released and RTCH is assigned for the converation }\end{array}$ & $\leq 1 \%$ \\
\hline
\end{tabular}




\subsection{Geographic Description of the Coverage Area}

Ondo State is located at the south western part of Nigeria which is an important zone of the country known for its commercial, educational, agricultural and political activities taking place around the area. Akure is the largest city and it is the capital of Ondo State situated at $7^{0} 25^{\prime}$ North Latitude, $5^{0} 19^{\prime}$ East Longitude. The city's projected population is 609,165 people for the year 2017. No previous work is available in literature on research carried out to investigate the quality of mobile phone services in the region. The quality of service measurements were collected from three major suburbs within Akure. The areas covered for this work are Federal University of Technology, Akure (FUTA), Alagbaka, and Oja - Arakale areas.

FUTA is the academic hub of the city, Alagbaka is a Government reserved area and therefore sparsely populated while Oja-Arakale area is the business district of the state and therefore densely populated. The different areas are chosen to help investigate the difference in quality of service based on population index of subscribers and average revenue per user (ARPU) status of the area.

\subsection{Drive Test Routes Survey}

The key areas covered around Alagbaka test route are Alagbaka Quarters, Police Command, Government Offices and Shoprite. The details of the test route is given in Figure 4. The FUTA campus and environment test route were covered as shown in Figure 5. The key areas covered are the major roads within FUTA and areas close to the two major gates including the University junction. The key areas covered in Oja Arakale area test route are: Oba Adesida road, Ojomu Street, Arakale Road and Ondo Road as shown in Figure 6.

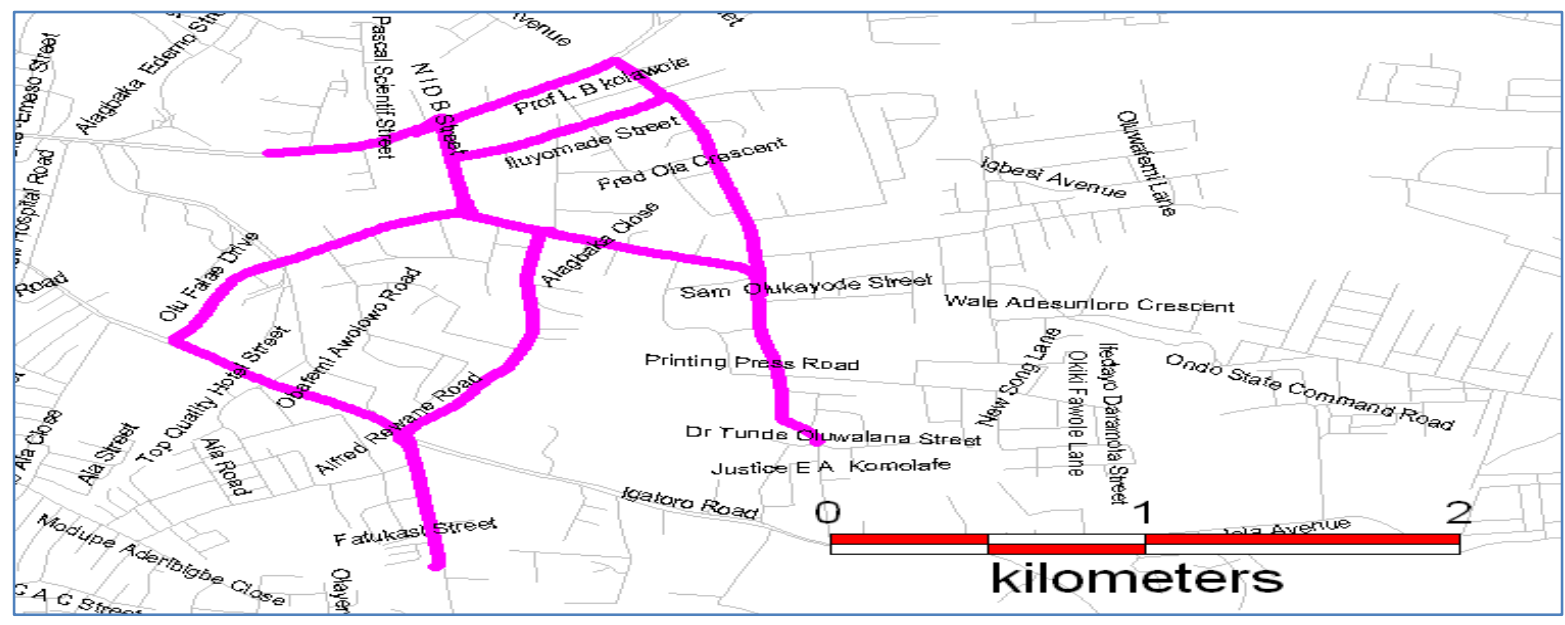

Figure 4: Alagbaka area test route

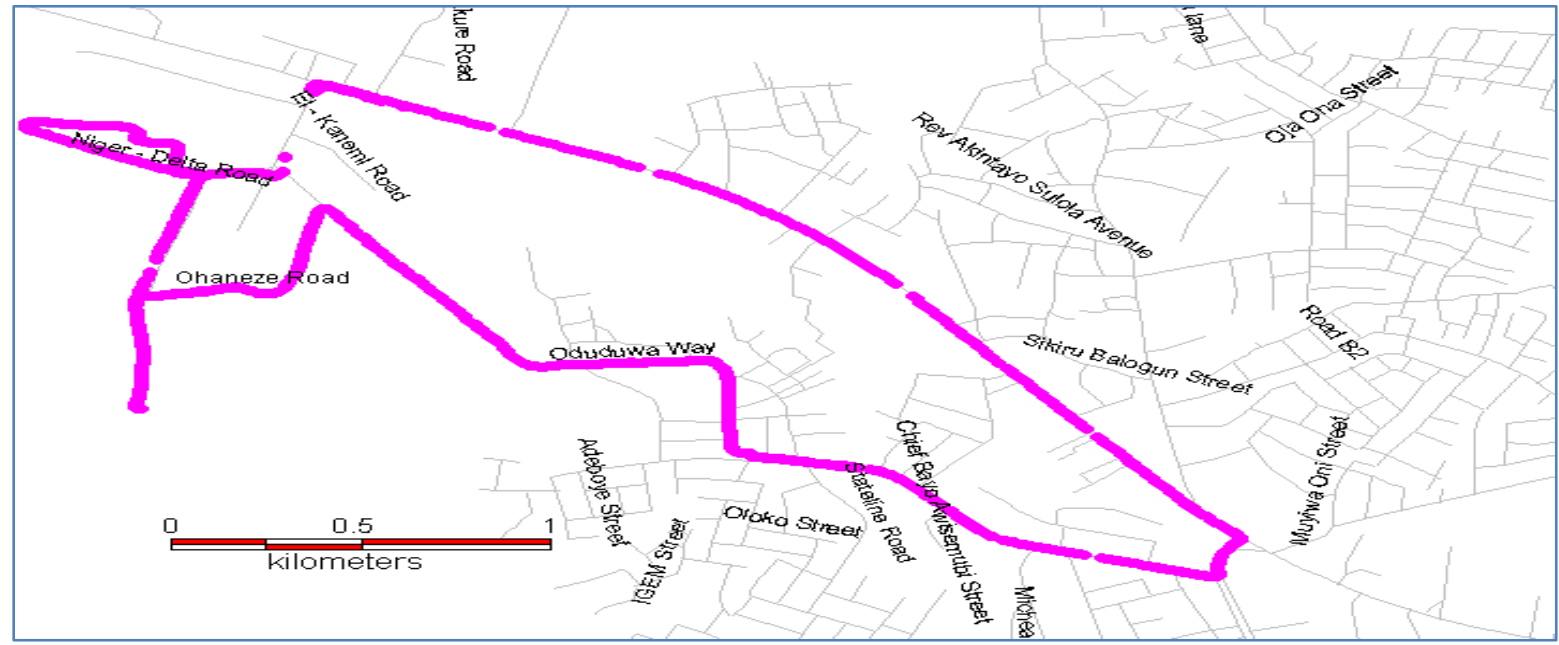

Figure 5: FUTA area test route 


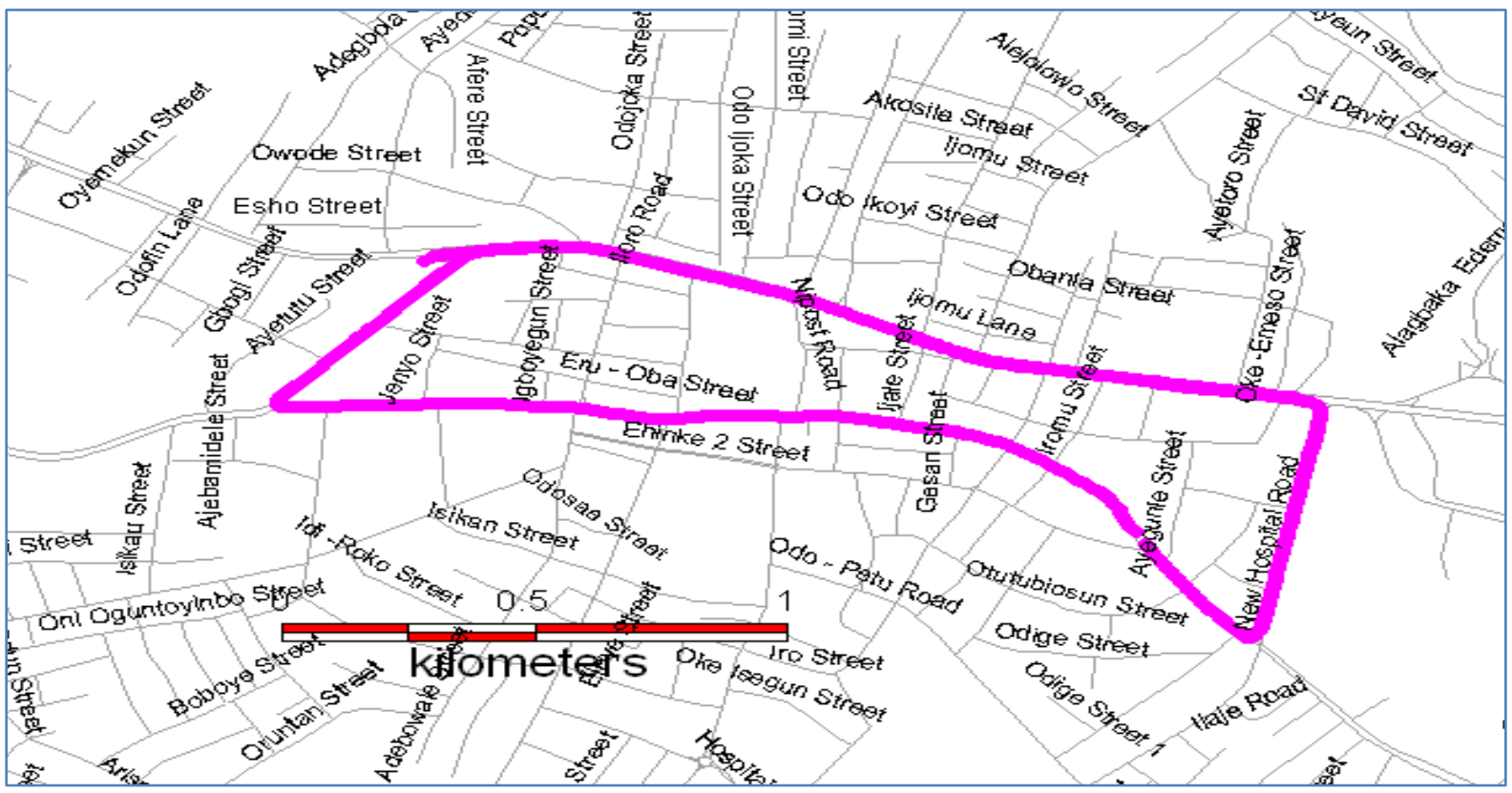

Figure 6: Oja - Arakale area test route

\subsection{Drive Test Measurement Collection}

Test data were collected from the four major mobile network operators in the country and will be referred to in this paper as MNO1, MNO2, MNO3 and MNO4. In terms of network signal coverage in Akure city there are $2 \mathrm{G}, 3 \mathrm{G}$ and $4 \mathrm{G}$ coverage. TEMS test phones used were locked on WCDMA/GSM Dual Mode access technology for all four mobile network operators considered. Data was collected for two - three hours every day, three times a day (morning, afternoon and evening data collection sessions) using the same test route.

\section{RESULT AND DISCUSSION}

Measurement collected during the drive test are summarized in Tables 1, 2 and 3 . In the tables the received signal code power (RSCP) for all the MNOs are documented. The other KPIs, namely Call set up success rate (CSSR), Call drop rate (CDR), Retainability and Soft Handover (SHO) success rate for the four networks considered are equally presented.

\subsection{Received Signal Code Power}

At the Alagbaka region, for the morning session, MNO1 had average measurements $50.89 \%$ above the benchmark of $-92 \mathrm{dBm}$ while MNO 2 and MNO3 had above 99\%. At the FUTA area, MNO1 performed averagely below the benchmark in the evening at $40.83 \%$ while MNO2, MNO3 and MNO4 had measurements $91.54 \%, 98 \%$ and $89.7 \%$ above the benchmark respectively. Around Oja-Arakale area, MNO2 had 100\% measurements above the benchmark and MNO1 had $68.91 \%$ in the morning; the least measurement of the area. MNO2 performed better at Oja-Arakale and FUTA areas while MNO3 performed better at the Alagbaka region. Overall, MNO2, MNO3 and MNO4 average received signal code power measurements were $90 \%$ above the benchmark. MNO1 has to increase its coverage area by increasing the number of base stations or increasing the power of her antennas if it is not already at the maximum approved range. Figures in Appendix A1, Figures 1-9 shows the RSCP plots of the Alagbaka, Oja-Arakale and FUTA test routes at different times of the day respectively.

Detailed analysis of the received signal strength (Received Signal Code Power- RSCP) and Energy per chip/Noise spectral density (EcNo) are presented in Tables A1-A6 in the Appendix. Figure 10, 11 and 12 shows the graphical presentation of the RSCP measurements of the mobile network operators at OjaArakale, Alagbaka and FUTA test route respectively.

Oja-Arakale area had the best average RSCP measurements across all networks. This might be because Oja-Arakale region is the business hub of the city and the best area to obtain an increasing average revenue per user (ARPU). It is also the best area to make a good impression and hence all networks put in their best to give optimal services at this area.

Looking at Figures 10-12 again, it will be noted that a large percentage of measurements from MNO1 were greater than -110 to -92 which signifies weak signal strength. With weak RSCP, subscribers will have more difficulties connecting to and maintaining the network link during calls. Averagely, all other networks performed well. 


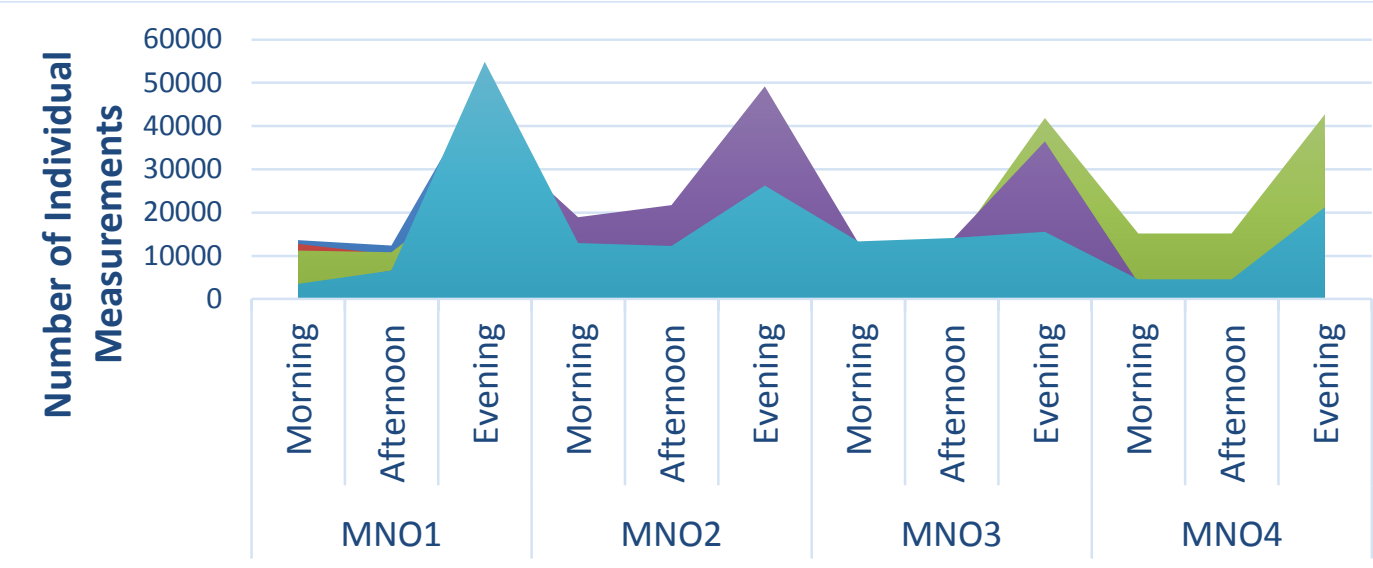

$\square-110$ to $-92 \square>-92$ to $-85 \square>-85$ to $-75 \square>-75$ to $-65 \square>-65$ to 0

Figure 10: RSCP analysis of the mobile network operators at Oja-Arakale area test route

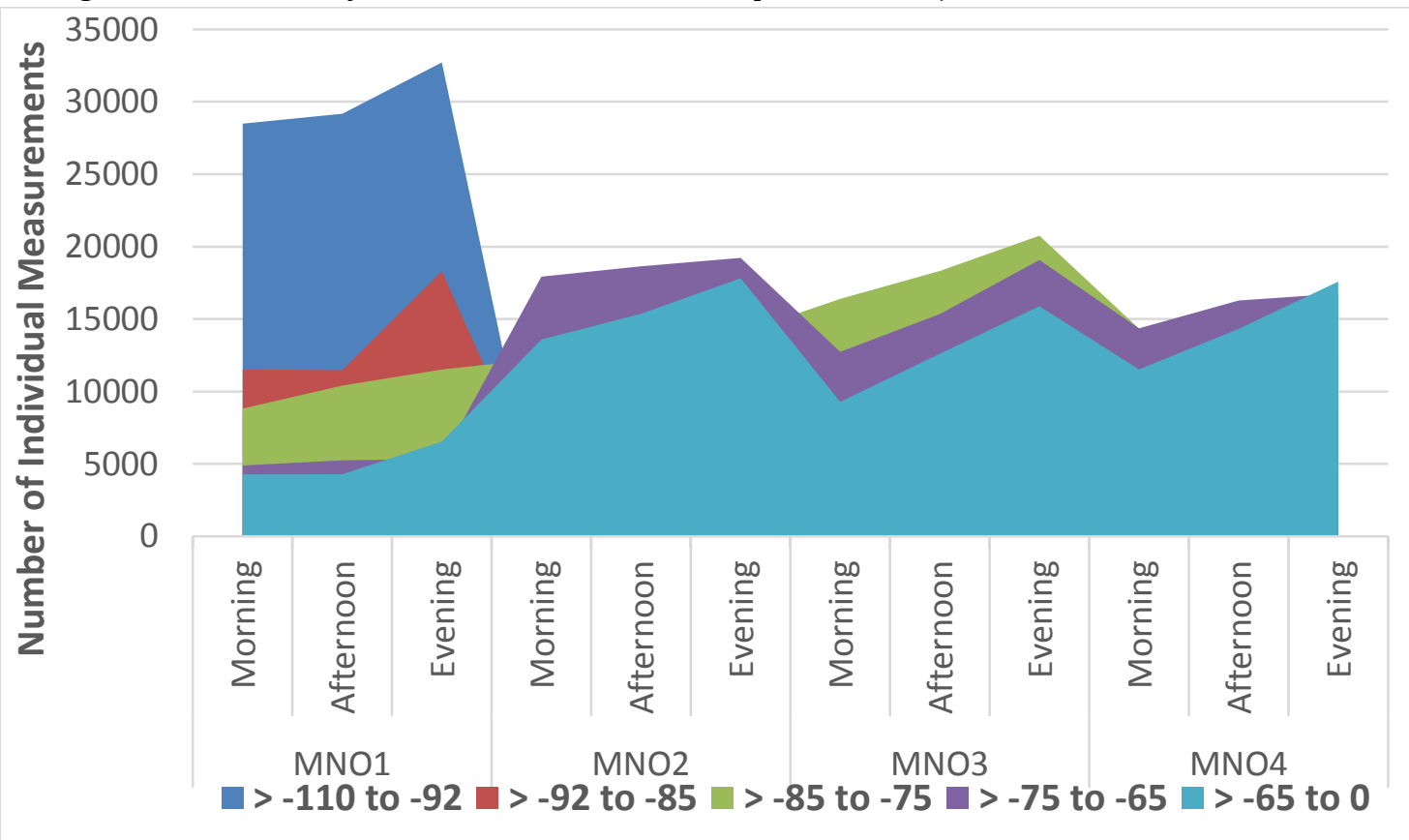

Figure 11: RSCP analysis of the mobile network operators at Alagbaka area test route

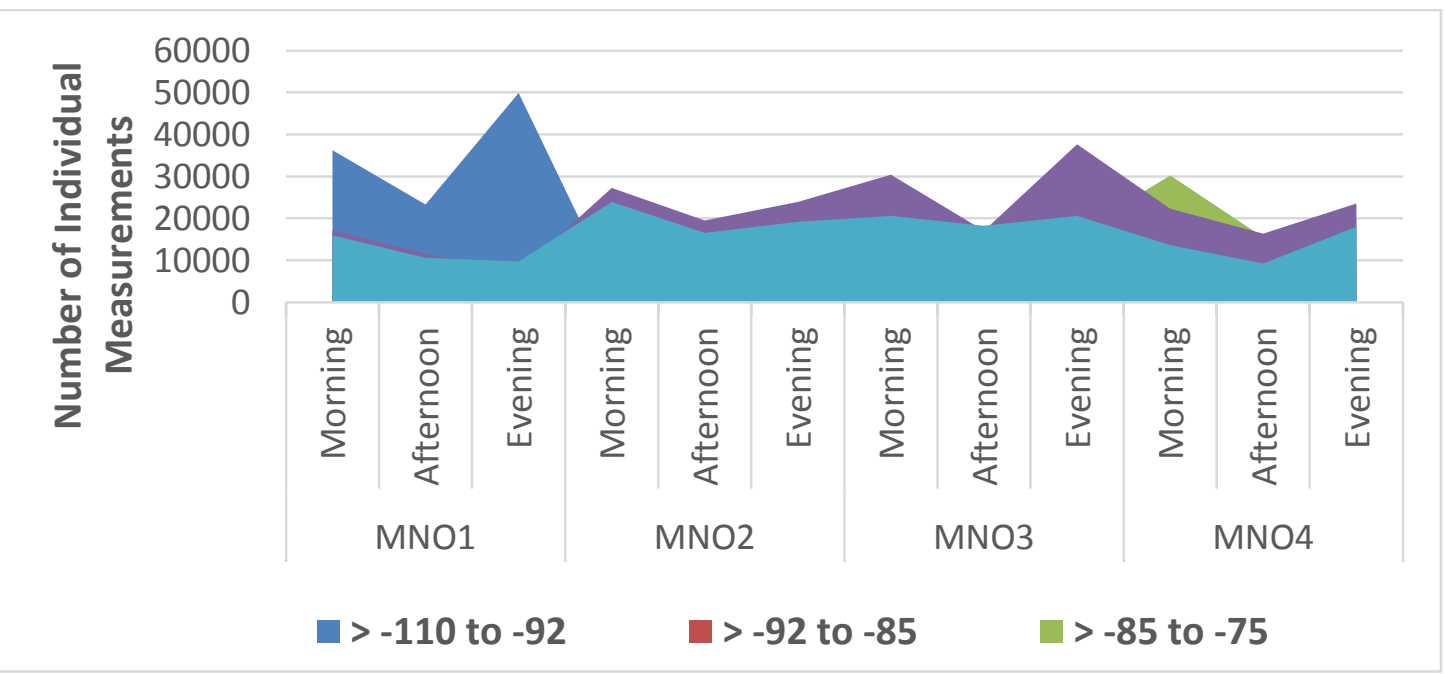

Figure 12: RSCP analysis of the mobile network operators at FUTA area test route 


\subsection{Call Set-up Success Rate (CSSR)}

Figure 13 shows a graphical presentation of the call set-up success rate (CSSR) analysis of the coverage areas. Some measurement showed that some voice services rendered by the MNOs had CSSR values below the target, with MNO1 offering the worst CSSR at FUTA area. CSSR measurements were worst in the morning and gave much better values in the evening. MNO4 had the worst CSSR of $57.89 \%$ at Alagbaka area in the morning while MNO3 performed consistently below the CSSR target of $98 \%$ at all the coverage areas at all times. Averagely, MNO2 gave the best CSSR of $98.25 \%$ while MNO1 and MNO4 had $90.13 \%$ and $95.11 \%$ respectively. Tables A7-A9 in the Appendix summarizes the KPI measurements of the mobile network operators at Oja-Arakale, Alagbaka and FUTA test route respectively.

\subsection{Call Drop Rate}

The target dropped call rate (CDR) given by NCC is $2 \%$ and from Figure 14 it can be seen that at five different instances, the MNOs had an overshoot above the target. MNO2 consistently gave an average CDR above the target at Alagbaka: 2.56\%, 2.86\% and 9.09\% for the morning, afternoon and evening measurements respectively. MNO1 had an overshoot at FUTA area in the morning and evening though worst in the morning with a value of $6.67 \%$ and $3.03 \%$ in the evening. There were no dropped calls at the 0ja-Arakale region and MNO4 had absolutely no dropped calls and performed best. MNO3 also performed well and had CDR below the target.

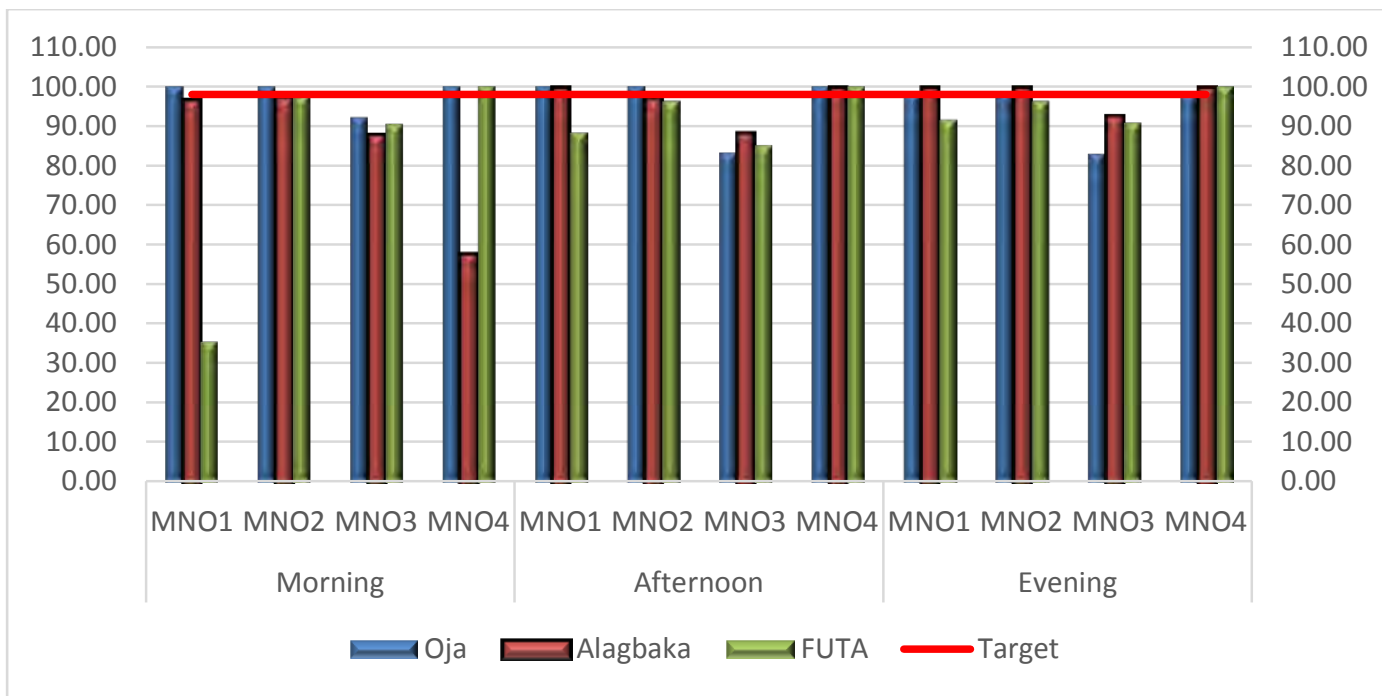

Figure 13: Call Setup Success Rate (CSSR) analysis of voice service provided by mobile network operators

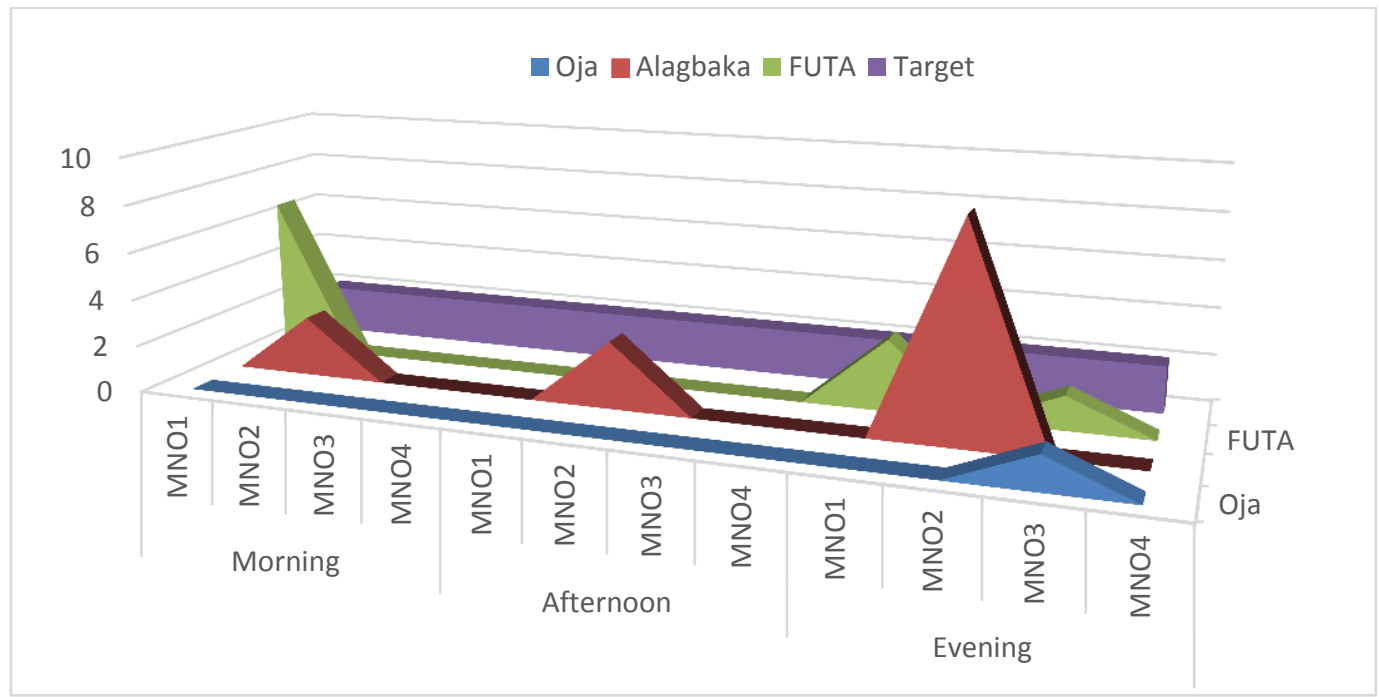

Figure 14: Call Drop Rate (CDR) analysis of voice service provided by mobile network operators 


\subsection{Call Completion Rate or Voice Service Retainability Ratio}

At the FUTA area, MNO1 gave a service retention ratio of $93.33 \%$ and $96.97 \%$ for the morning and evening measurements which is below the target of $100 \%$ specified by NCC. MNO2 peformed below the target at Alagbaka for morning, afternoon and evening sessions; 97.44\%, $97.14 \%$ and $90.91 \%$ respectively. While MNO3 had a retainability ratio below the target at 0jaArakale area in the evening with $98.55 \%$.

\subsection{Other Key Performance Indicators (Kpi) Analysis}

Soft handover (SHO) success rate was 100\% across all mobile network operators for all areas and at all times. This signifies that all the base stations performed optimally considering the SHO. Radio resource control (RRC) protocol functions includes: establishing connection, release funtion, broadcast information, radio bearer establishment etc. RCC congestion rate was $100 \%$ for MNO 3 for all areas and at all times. MNO4 also had 100\% RRC connection rate at all areas in the afteroon and evening, this is shown in Figure 16. The morning measurement for MNO 4 in the morning at FUTA region was below $60 \%$. MNO1 gave the worst RCC congestion rate in the evening and performed much better in the morning and afternoon.

Critically evaluating the measurements, MNO1 had an average CSSR of $90.13 \%$ and overshoot CDR at FUTA area in the morning and evening, with average value of $1.07 \%$. The average retention ratio was $98.92 \%$

MNO2 gave the best CSSR of $98.25 \%$ but consistently gave an average CDR above $2 \%$ at Alagbaka area: $2.56 \%, 2.86 \%$ and $9.09 \%$ and retainability ratio below the target of $97.44 \%, 97.14 \%$ and $90.91 \%$ for the morning, afternoon and evening measurements respectively. MNO2 had an average CDR and retainability rato of $1.61 \%$ and $98.84 \%$ respectively.

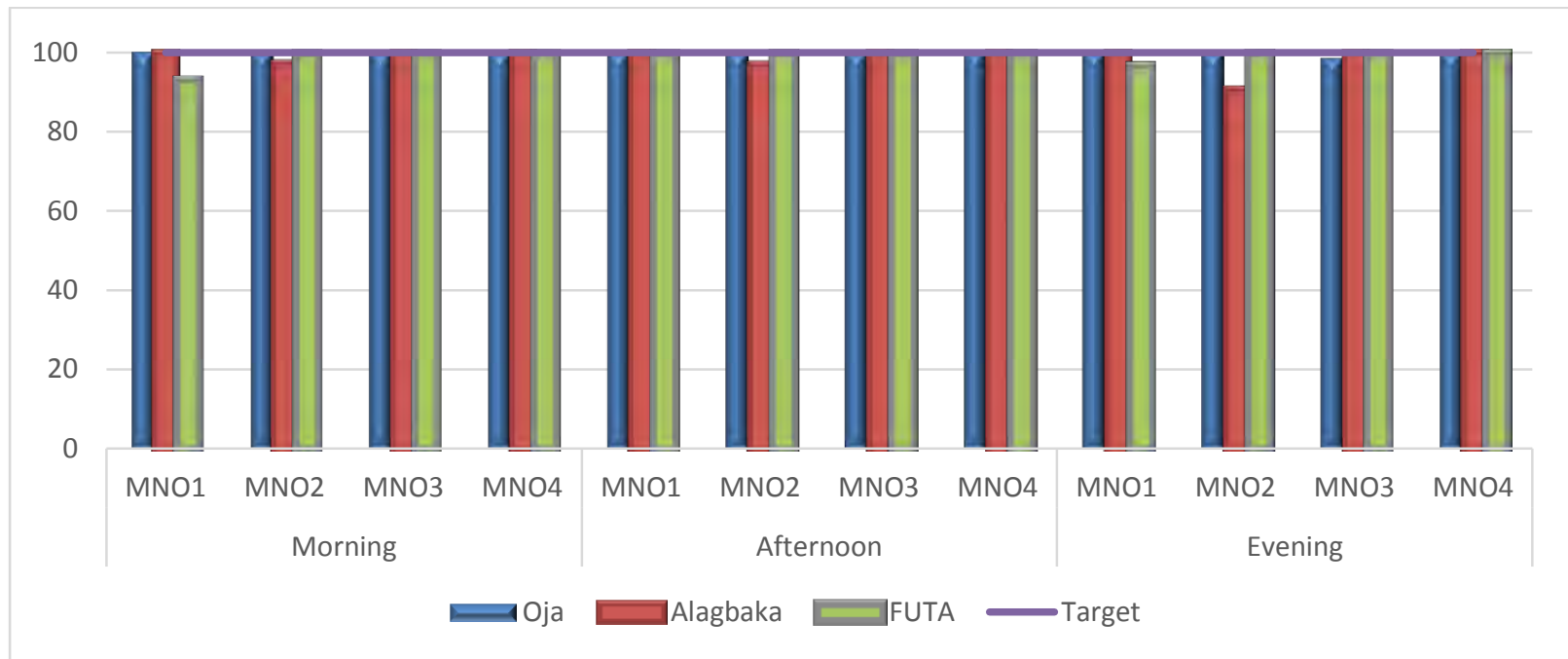

Figure 15: Retainability Ratio analysis of voice service provided by mobile network operators

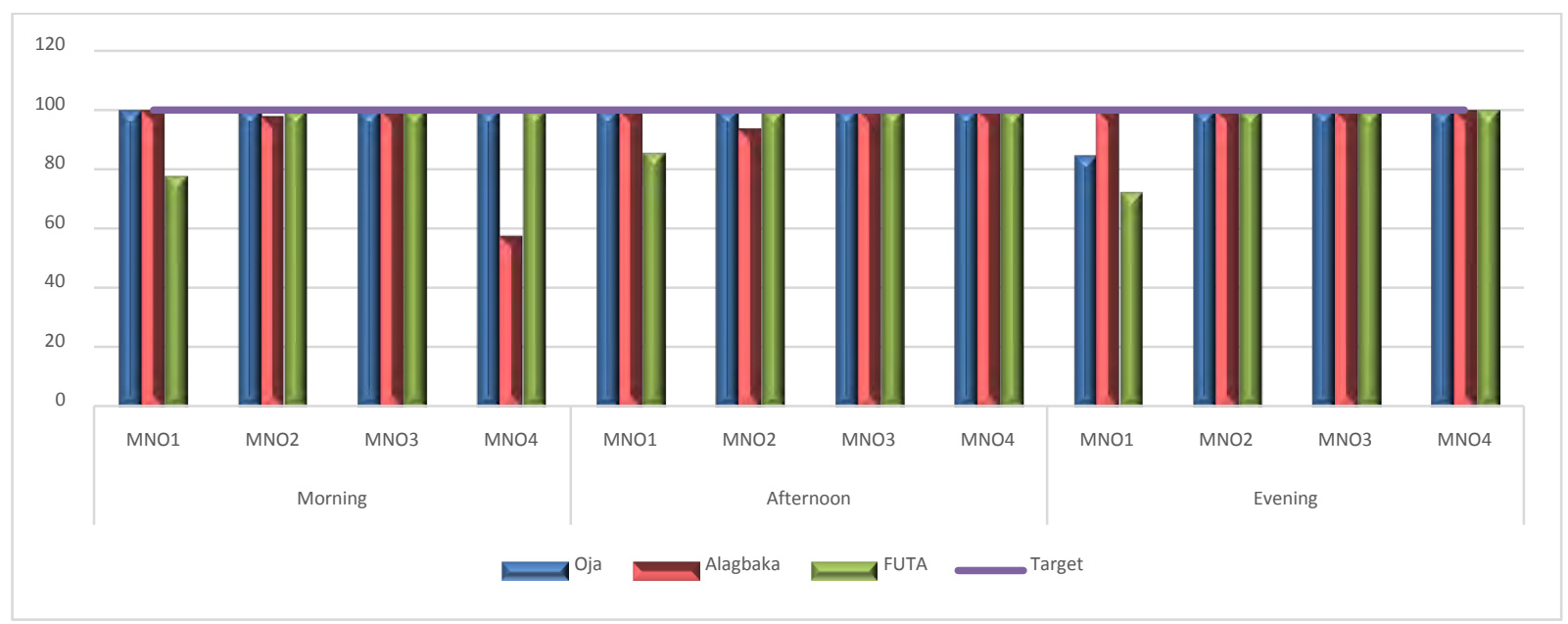

Figure 16: Radio Resource Congestion Rate provided by mobile network operators 
MNO3 had the worst CSSR of $88.33 \%$ and performed below the target at all the coverage areas at all times but once the subscriber is connected, the call drop rates were minimal and below $2 \%$. The retainability ratio was normal except at the 0ja-Arakale area where it was 98.55\%.

MNO4 had an average CSSR value of $95.11 \%$ which is below the target of $98 \%$, which was due to a very low CSSR value at FUTA area in the morning with of $57.89 \%$. For all other times, the CSSR value for MNO4 was above $98 \%$. MNO4 had absolutely no dropped calls and performed best and consistently gave a retainability ratio above the target.

\section{CONCLUSION}

This paper presents QoS data and analysis which compares QoS offered at different times of the day, covering three coverage areas and offered by different mobile network operators. There is a difference across networks in the performance of voice services based on the time of the day and the area under consideration. No mobile network operator offered services that met the required quality of service specified by the Nigerian Communication Commission (NCC) for data collected within three days and selected times of the day. The CSSR and CDR values were above the threshold of $98 \%$ for the former and below $2 \%$ for the later. The summarized analysis presented on the NCC website must be a reflection of what is happening at most areas of the country. Whereby when the measurements from the business hub of the country (Lagos, Abuja, Kano and Port-harcourt) are averaged with the measured values collected from other areas (such as Akure) the failure to meet specified quality of service metrics becomes less obvious. It is therefore important for stakeholders to use performance metric measurements for different regions of the country to make informed decisions instead of the lumped sum. Voice services rendered by mobile network operators to subscribers should be improved and customers should get value for their money.

\section{REFERENCES}

[1] Nigerian Communication Commission (NCC) Retrieved from https://www.ncc.gov.ng on 25/03/2018

[10] Adegoke A. S and Babalola I, T. "Quality of service of GSM telephone system in Nigeria, American Journal of scientific and Industrial research", Vol. 2, Issue 5, pp 707-712, 2011.
[11] Popoola S. I., Atayero A. A., Faruk N., Badejo J. A. () "Data on the Key Performance Indicators for Quality of Service of GSM Networks in Nigeria", Data in Brief, Elsevier, Vol. 16, pp. 914-928, 2017.

[12] Haider, B., Zafrullah, M. \& Islam, M. K. "Radio Frequency Optimization \& QoS Evaluation in Operational GSM Network". Proceedings of the World Congress on Engineering and Computer Science, Vol. I, October 20-22, 2009, San Francisco, USA.

[13] ITU-T recommendation G.1000 Retrieved from https://www.itu.int/rec/dologin pub.asp?lang=e\&id=T-REC-G.1000-200111I!!PDF-E\&type=items on 25/03/2018, 2001

[2] Deyu L. "Data Mining Approach To Analyze Mobile Telecommunications Network Quality of Service: The Case of Ethiotelecom", Msc Thesis, School of Graduate Studies School of Information Science, Addis Ababa University 2014.

[3] Dahunsi F. M. and Kolawole G., "Participatory Analysis of Cellular Network Quality of Service", International Journal of Computing and ICT Research, Vol. 9, Issue 1, pp 25 - 40, 2015.

[4] Oseni O.F, Popoola S. I, Enumah H, Gordian A., "Radio Frequency Optimization of Mobile Networks in Abeokuta, Nigeria for Improved Quality of Service", International Journal of Research in Engineering and Technology, Vol. 03, number 8, 2009,

[5] Kuboye B.M., Alese B.K., and Fajuyigbe 0. "Congestion Analysis on the Nigerian Global System for Mobile Communications (GSM) Network", the Pacific Journal of Science and Technology, Vol. 10, Number 1, 2009.

[6] Popoola, J. J., Megbowon, I. O., and Adeloye, V. S. A., "Performance Evaluation and Improvement on Quality of Service of Global System for Mobile Communications in Nigeria". Journal of Information Technology Impact, Vol. 9, No. 2, pp. 91-106, 2009.

[7] Emeruwa, C., "Comparative Analysis of signal strengths of some cellular networks in Umuahia, Eastern Nigeria", Quest Journals, Journal of Electronics and Communication Engineering Research, Vol. 2, Number 10, pp 01-05, 2015.

[8] Ozovehe A. and Usman A.U. "Performance analysis of GSM Networks in Minna Metropolis of Nigeria", Nigerian Journal of Technology (NIJOTECH), Vol. 34, No. 2, 2015, pp. 359-367.

[9] Kyriazakos, S., Papaoulakis, N., Nikitopoulos, D., Gkroustiotis, E., Kechagias, C., Karambalis, C., and Karetsos, G., A Comprehensive Study and Performance Evaluation of Operational GSM and GPRS Systems under Varying Traffic Conditions" $1^{\text {st }}$ Mobile and Wireless Telecommunications Summit, Greece, 2002 


\section{APPENDIX}

\section{A1. RSCP Plot}

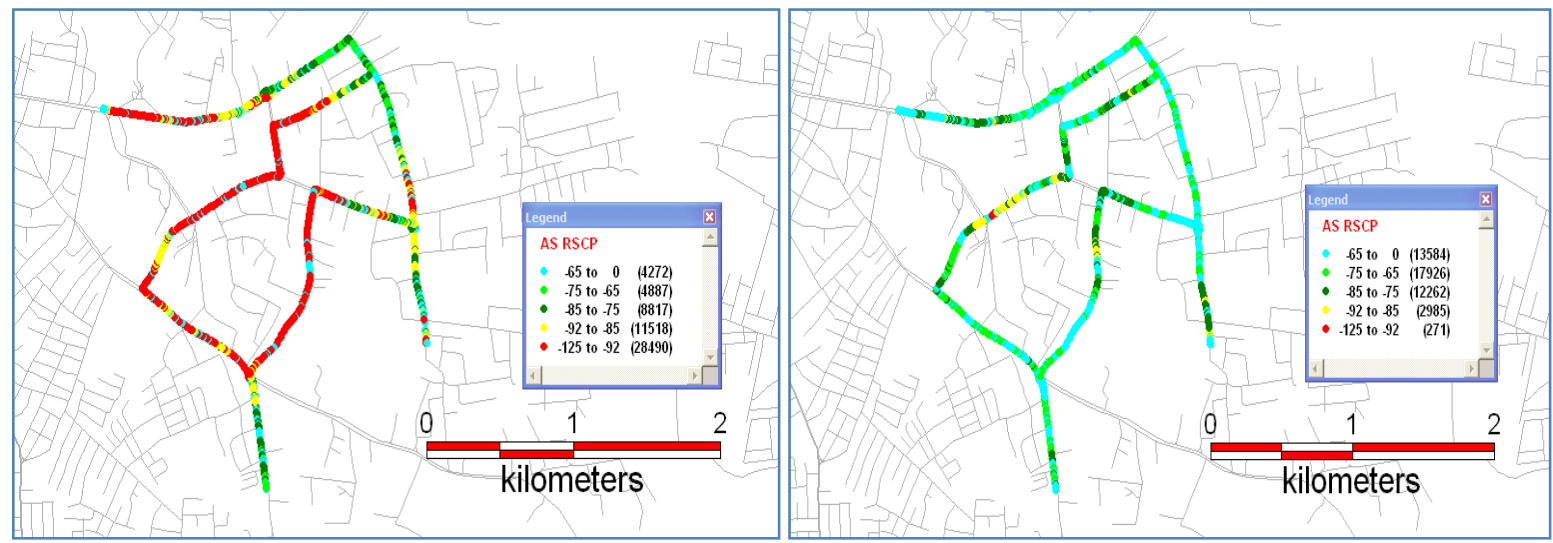

Figure 1a: MNO1 RSCP Plot Alagbaka Morning

Figure 1b: MNO2 RSCP Plot Alagbaka Morning
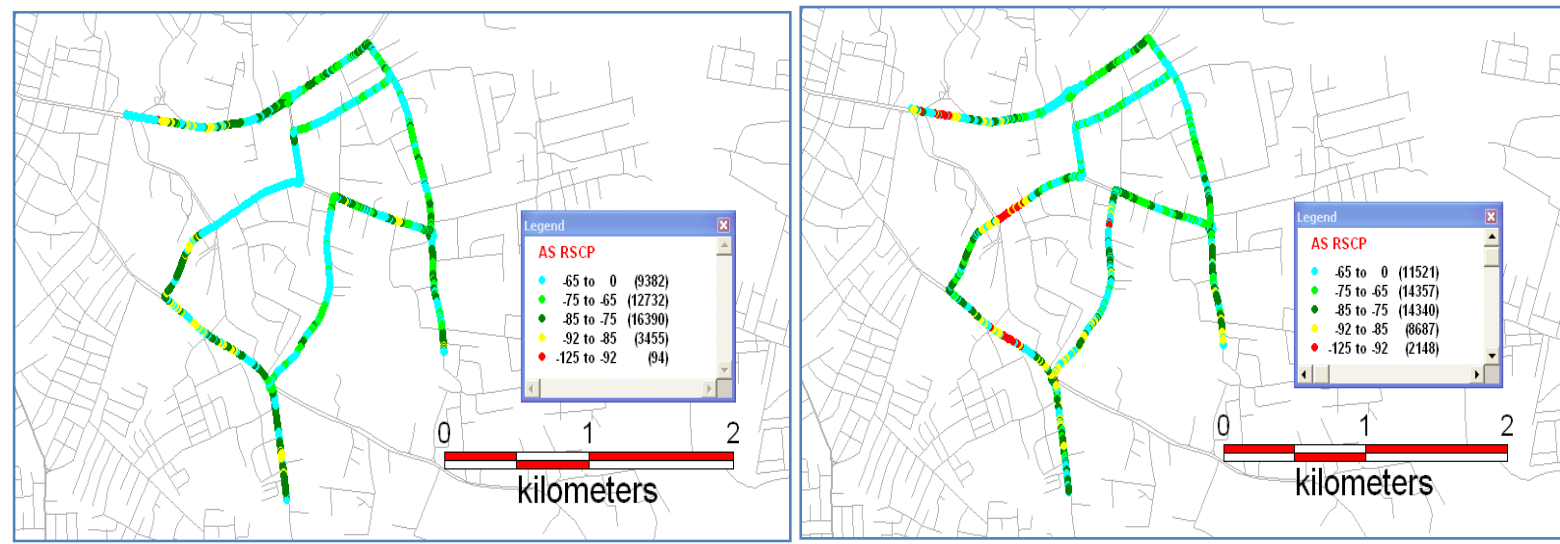

Figure 1c: MNO3 RSCP Plot Alagbaka Morning

Figure 1d: MNO4 RSCP Plot Alagbaka Morning
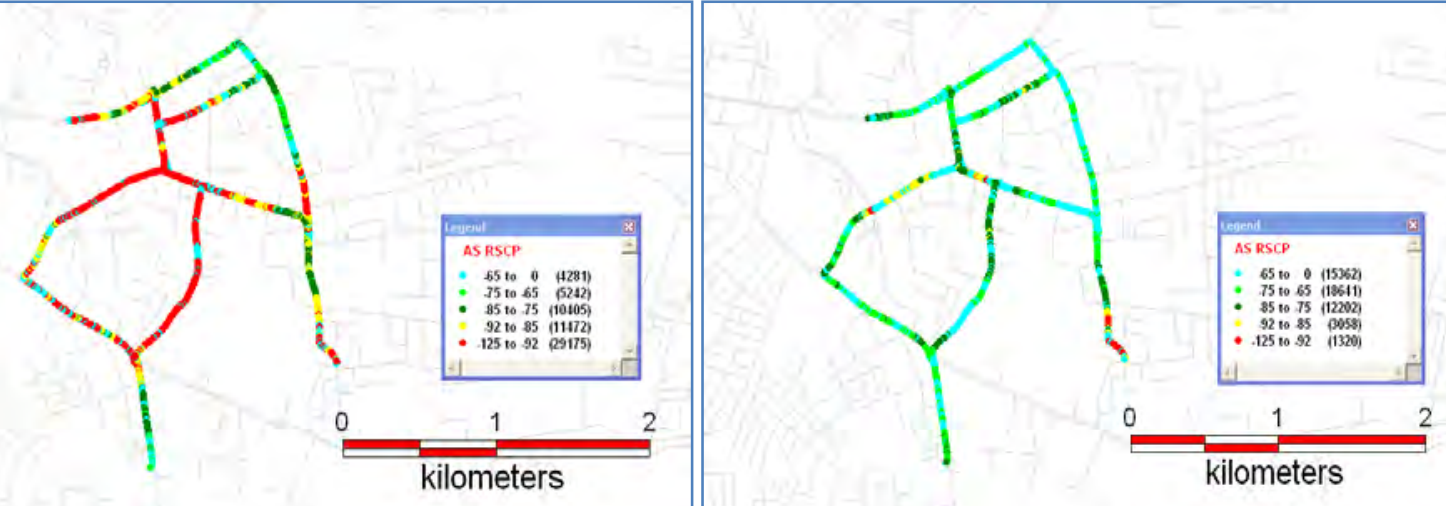

Figure 2a: MNO1 RSCP Plot Alagbaka Afternoon
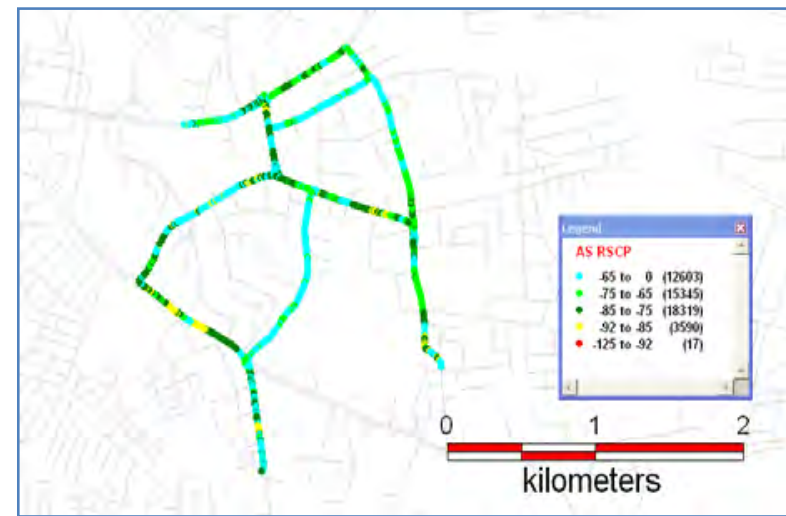

Figure 2b: MNO2 RSCP Plot Alagbaka Afternoon

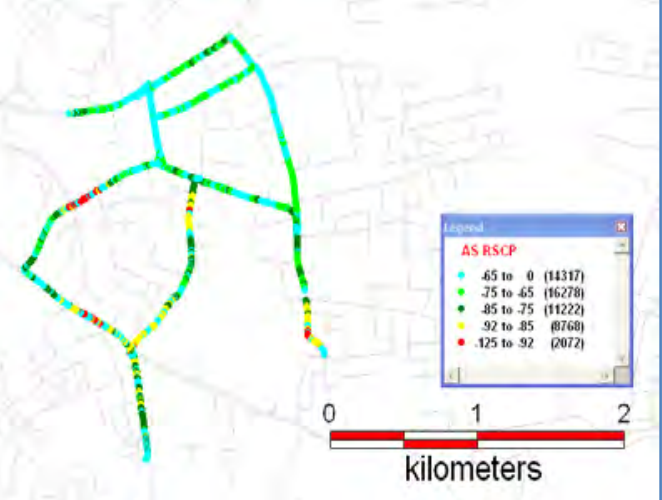

Figure 2c: MNO3 RSCP Plot Alagbaka Afternoon Figure 2d: MNO4 RSCP Plot Alagbaka Afternoon 


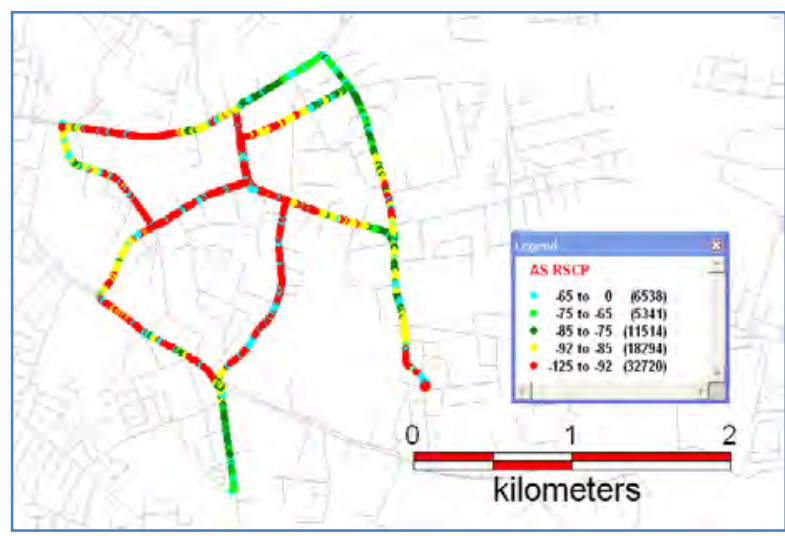

Figure 3a: MNO1 RSCP Plot Alagbaka Evening

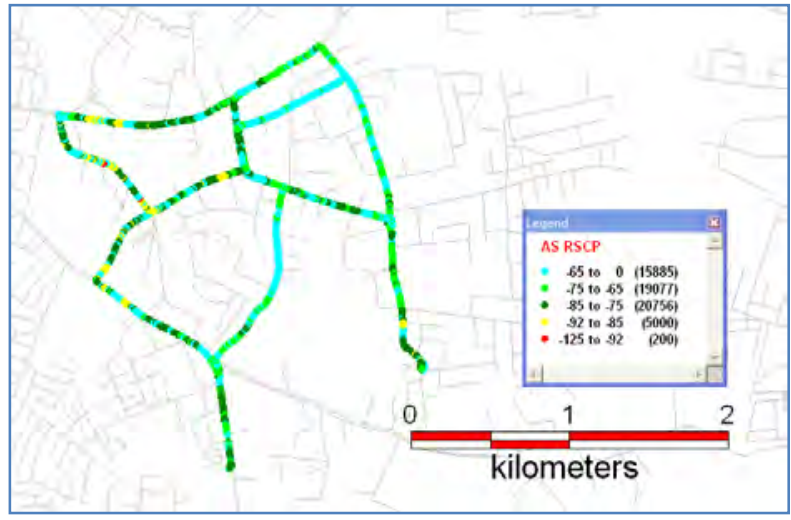

Figure 3c: MNO3 RSCP Plot Alagbaka Evening

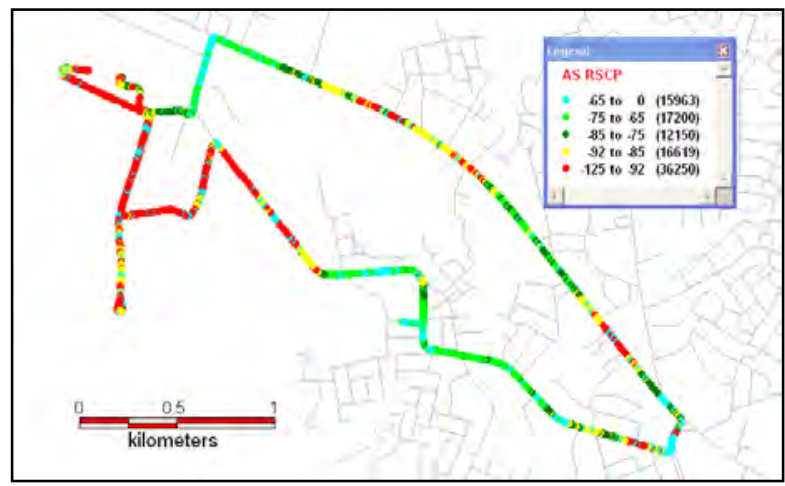

Figure 4a: MNO1 RSCP Plot FUTA Morning

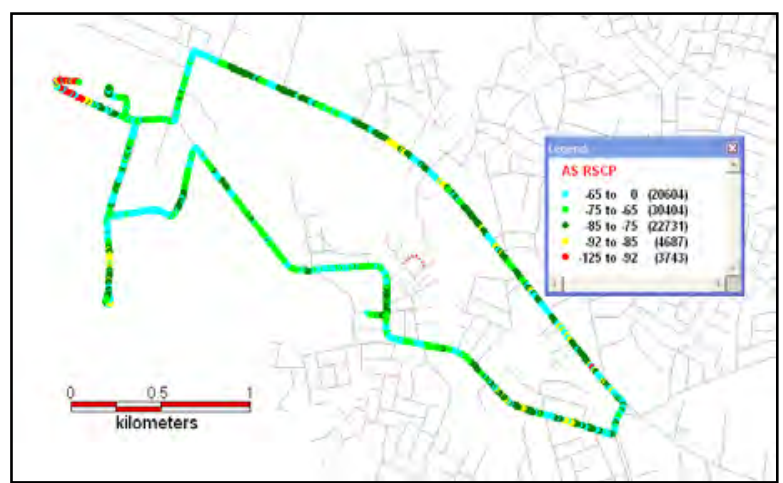

Figure 4c: MNO3 RSCP Plot FUTA Morning

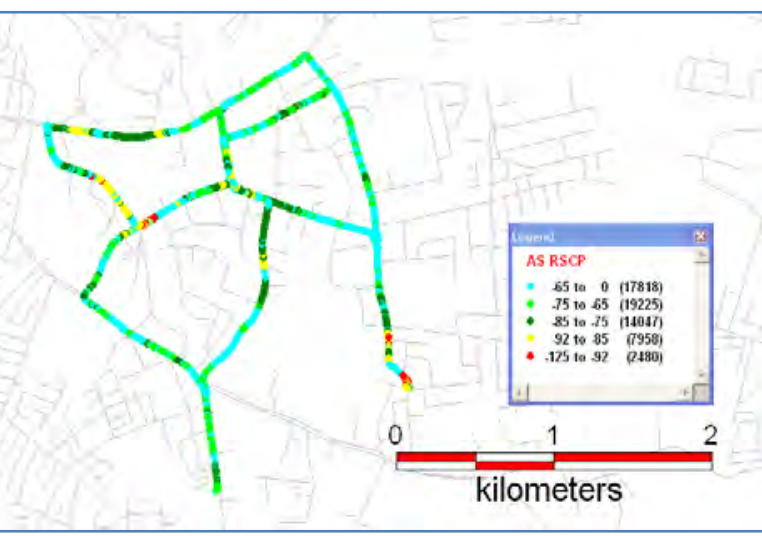

Figure 3b: MNO2 RSCP Plot Alagbaka Evening

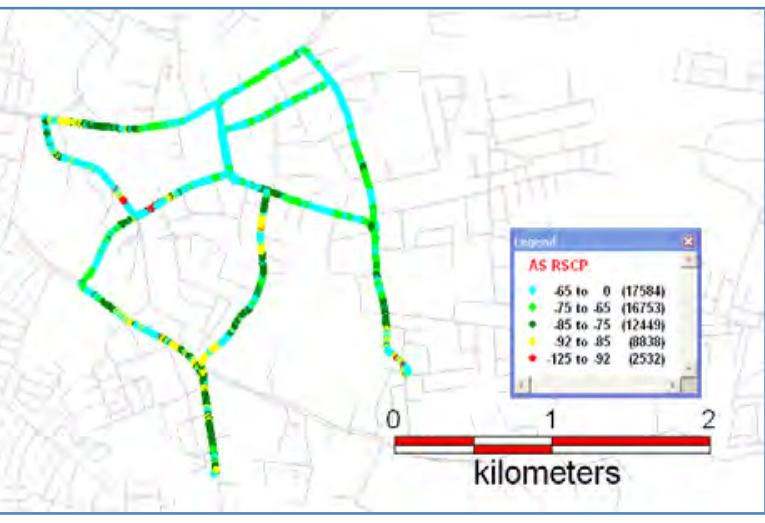

Figure 3d: MNO4 RSCP Plot Alagbaka Evening

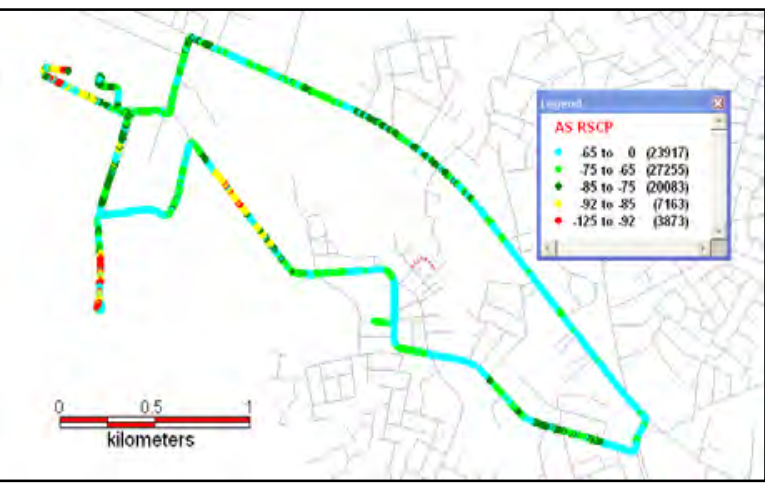

Figure 4b: MNO2 RSCP Plot FUTA Morning

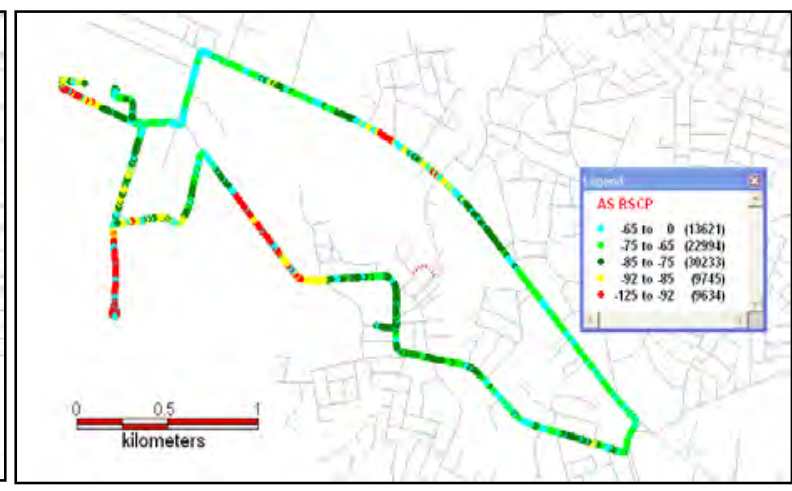

Figure 4d: MNO4 RSCP Plot FUTA Morning 


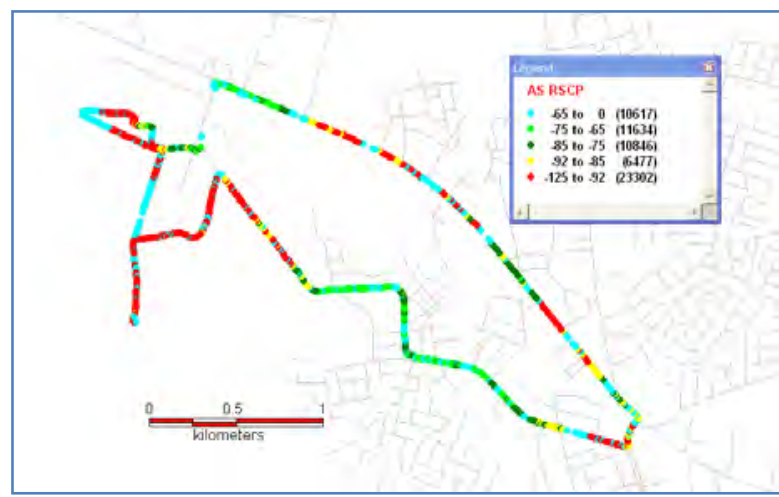

Figure 5a: MNO1 RSCP Plot FUTA Afternoon

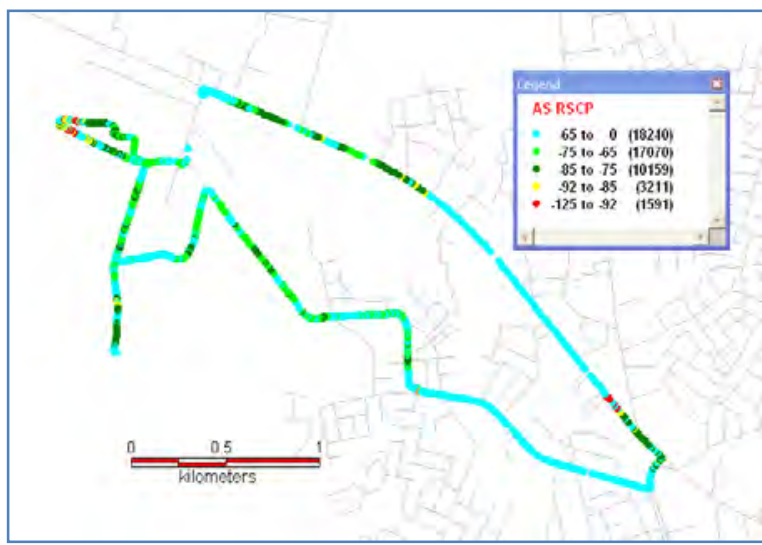

Figure 5c: MNO3 RSCP Plot FUTA Afternoon

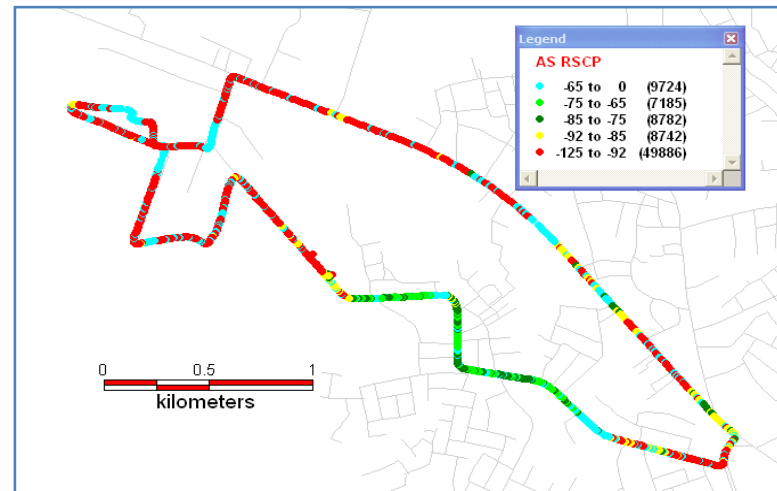

Figure 6a: MNO1 RSCP Plot FUTA Evening

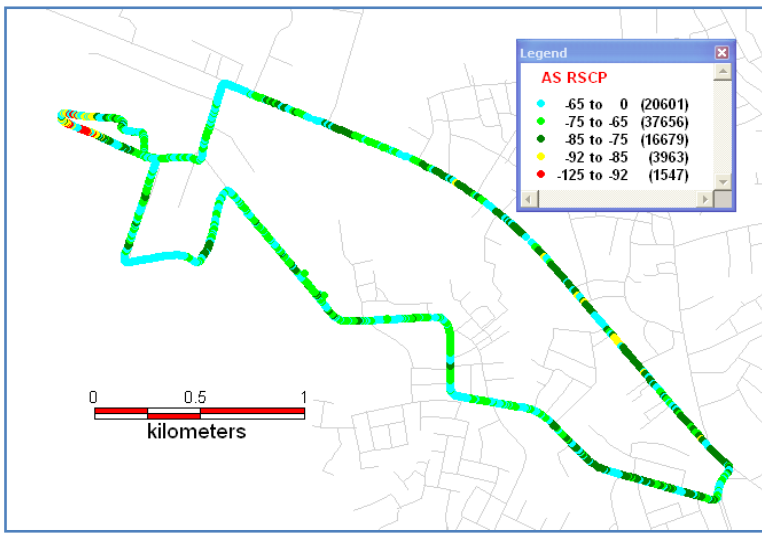

Figure 6c: MNO3 RSCP Plot FUTA Evening

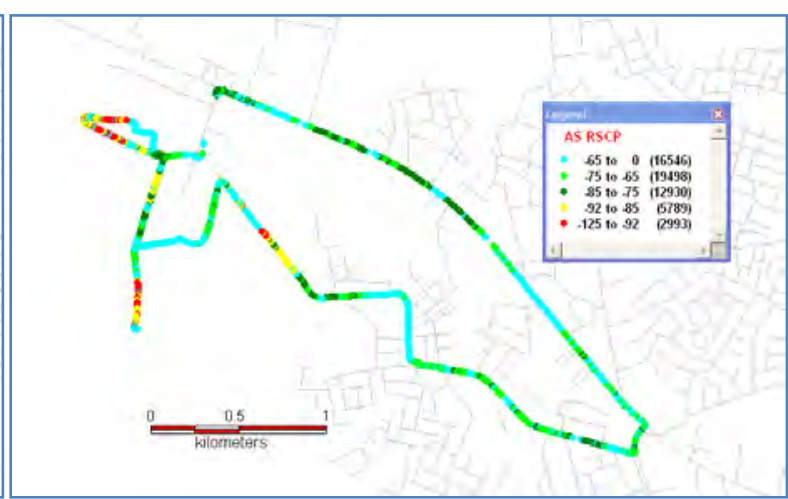

Figure 5b: MNO2 RSCP Plot FUTA Afternoon

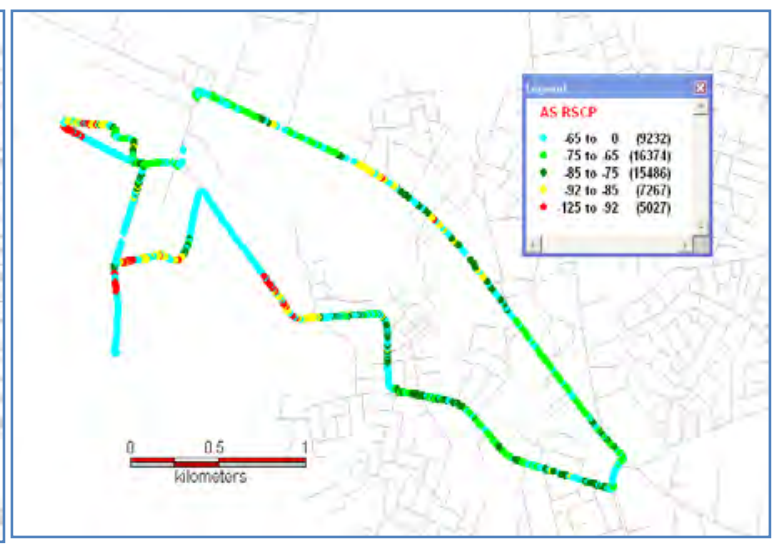

Figure 5d: MNO4 RSCP Plot FUTA Afternoon

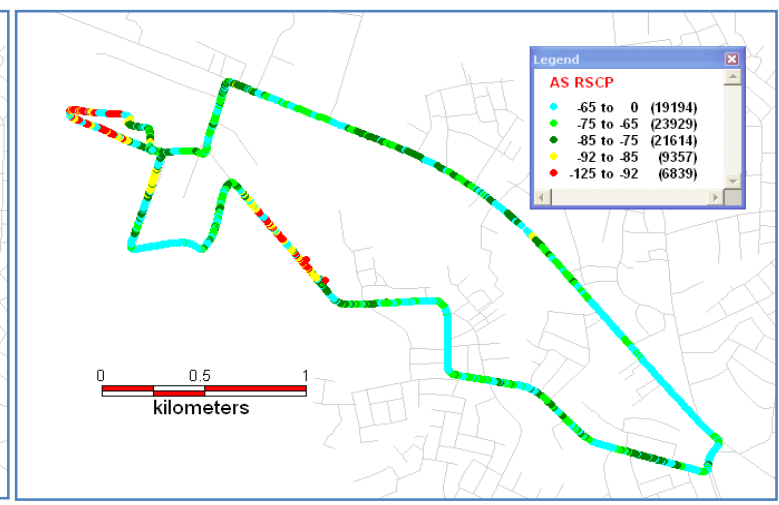

Figure 6b: MNO2 RSCP Plot FUTA Evening

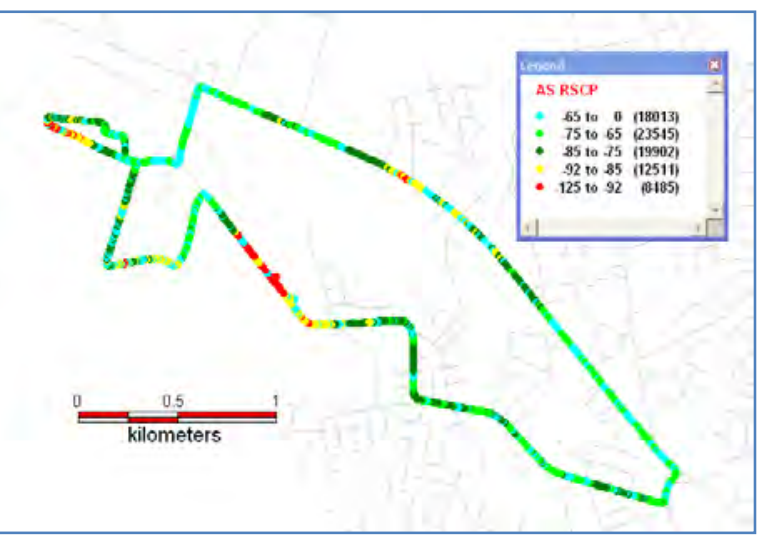

Figure 6d: MNO4 RSCP Plot FUTA Evening 

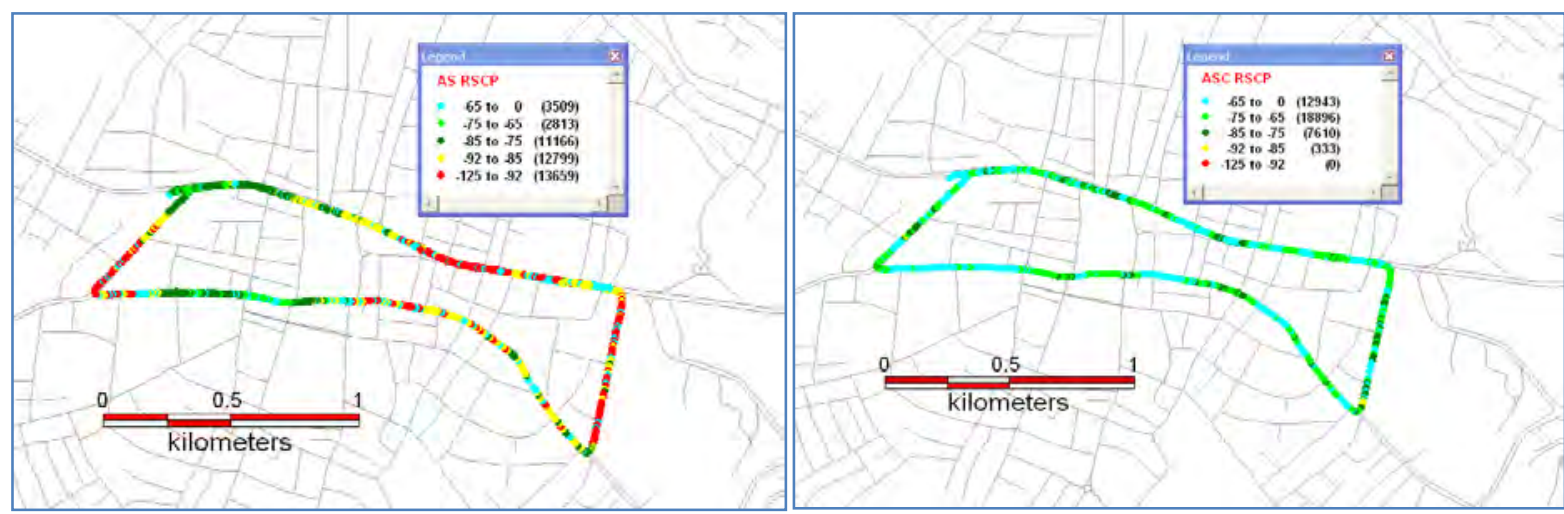

Figure 7a: MNO1 RSCP Plot Oja-Arakale Morning Figure 7b: MNO2 RSCP Plot Oja-Arakale Morning
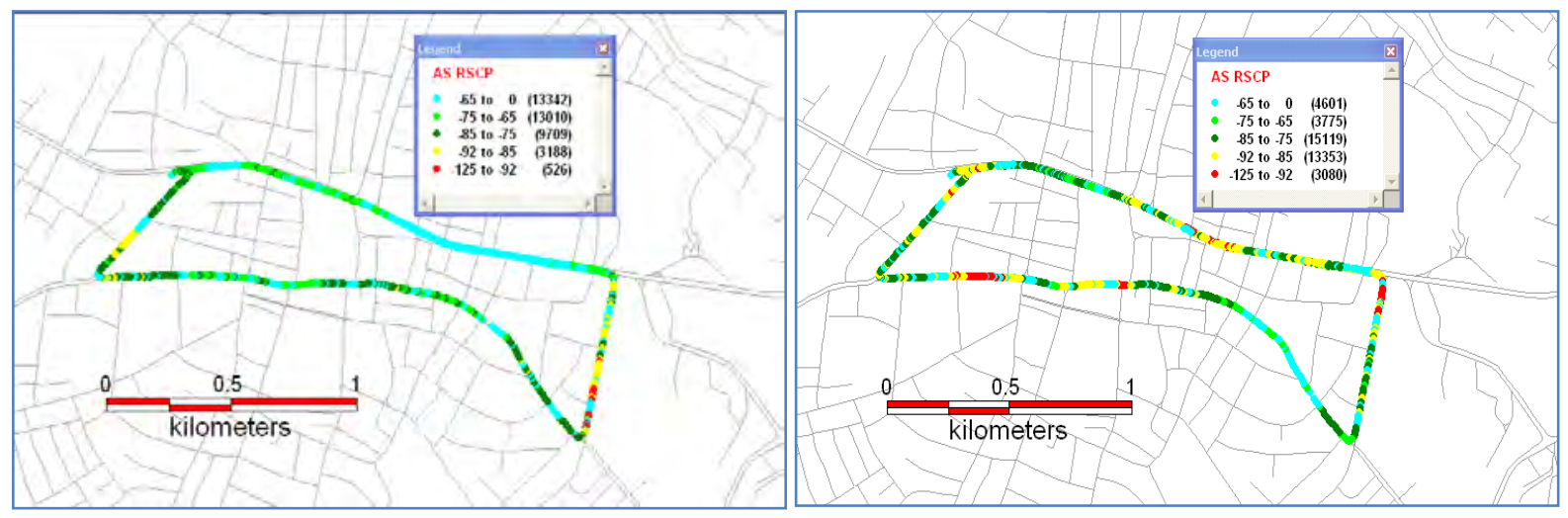

Figure 7c: MNO3 RSCP Plot Oja-Arakale Morning Figure 7d: MNO4 RSCP Plot Oja-Arakale Morning

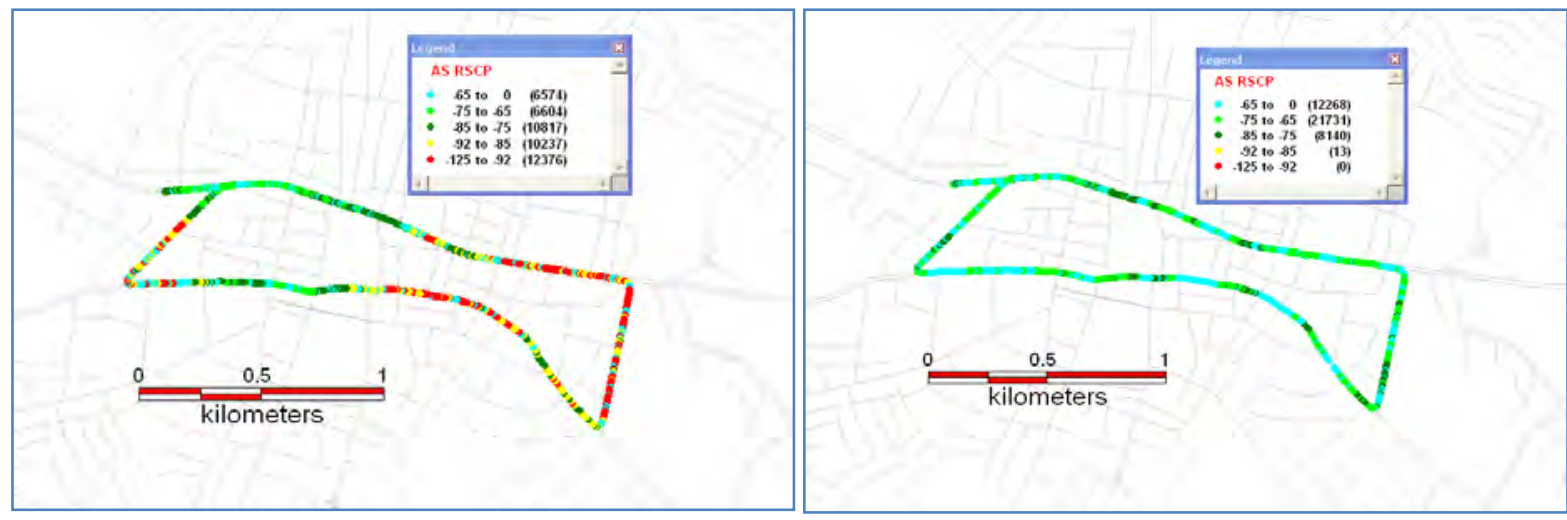

Figure 8a: MNO1 RSCP Plot Oja-Arakale Afternoon Figure 8b: MNO2 RSCP Plot Oja-Arakale Afternoon
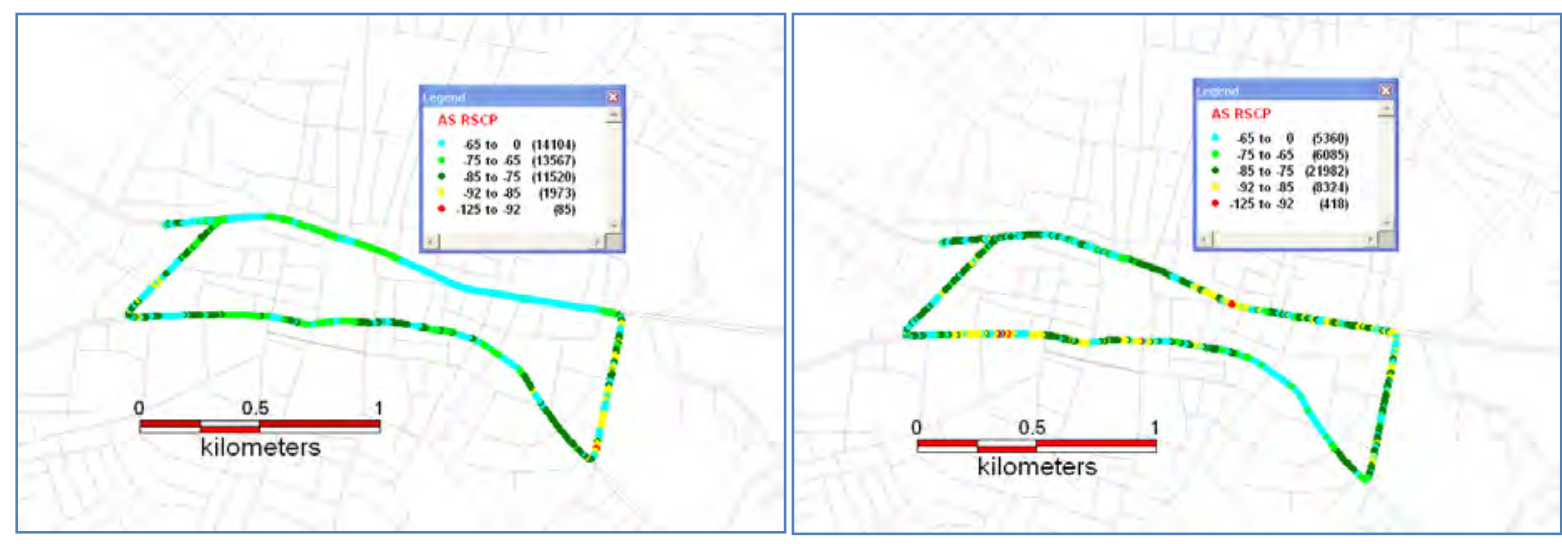

Figure 8c: MNO3 RSCP Plot Oja-Arakale Afternoon Figure 8d: MNO4 RSCP Plot Oja-Arakale Afternoon 


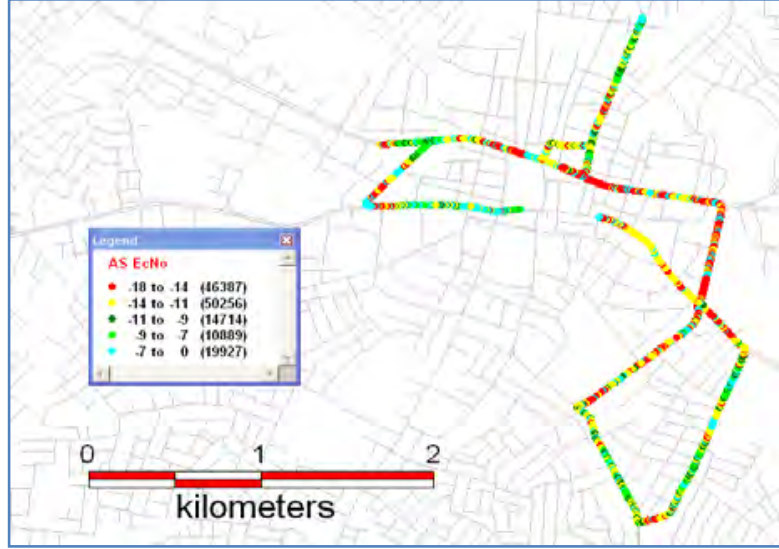

Figure 9a: MNO1 RSCP Plot Oja-Arakale Evening
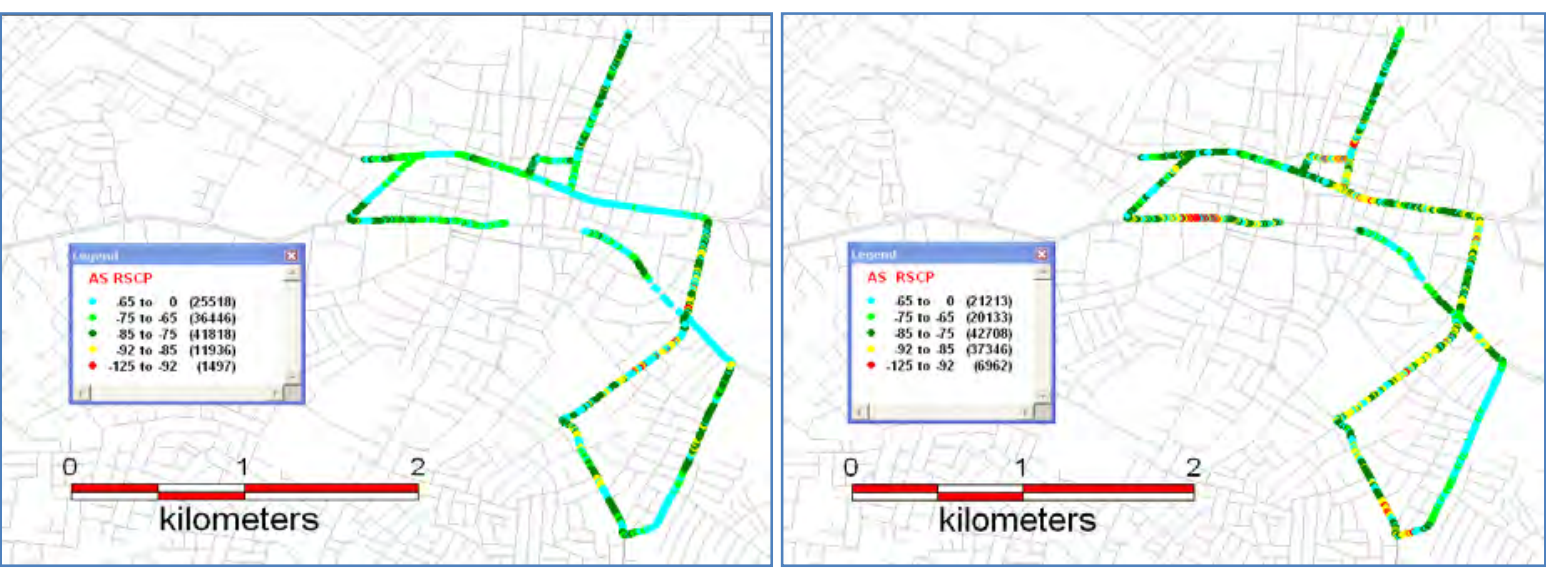

Figure 9c: MNO3 RSCP Plot Oja-Arakale Evening Figure 19d: MNO4 RSCP Plot Oja-Arakale Evening

\section{A2. RSCP measurements}

For Table A1 - A6, "Morn", "After" and "Even" stands for Morning, Afternoon and Evening

Table A1: Number of measurements against RSCP range at the Alagbaka area

\begin{tabular}{c|ccc|ccc|ccc|ccc}
\hline & \multicolumn{3}{|c|}{ MNO1 } & \multicolumn{3}{c|}{ MNO2 } & \multicolumn{3}{c|}{ MNO3 } & \multicolumn{3}{c}{ MNO4 } \\
\hline RSCP $(\mathrm{dbm})$ & Morn & After & Even & Morn & After & Even & Morn & After & Even & Morn & After & Even \\
\hline$>-110$ to -92 & 28490 & 29175 & 32720 & 271 & 1320 & 2480 & 94 & 17 & 200 & 2148 & 2027 & 2532 \\
$>-92$ to -85 & 11518 & 11472 & 18294 & 2985 & 3058 & 7958 & 3455 & 3590 & 5000 & 8687 & 8768 & 8838 \\
$>-85$ to -75 & 8817 & 10405 & 11514 & 12262 & 12202 & 14047 & 16390 & 18319 & 20756 & 14340 & 11222 & 12449 \\
$>-75$ to -65 & 4889 & 5242 & 5341 & 17926 & 18641 & 19225 & 12732 & 15345 & 19077 & 14357 & 16278 & 16753 \\
$>-65$ to 0 & 4272 & 4281 & 6538 & 13584 & 15362 & 17818 & 9282 & 12603 & 15885 & 11521 & 14317 & 17584 \\
\hline$\%$ RSCP $>=92 \mathrm{dbm}$ & 50.89 & 51.83 & 56.2 & 99.42 & 97.39 & 95.96 & 99.77 & 99.96 & 99.67 & 95.79 & 96.14 & 95.64 \\
\hline
\end{tabular}

Table A2: Number of measurements against EcNo range at the Alagbaka area

\begin{tabular}{|c|c|c|c|c|c|c|c|c|c|c|c|c|}
\hline & \multicolumn{3}{|c|}{ MN01 } & \multicolumn{3}{|c|}{ MNO2 } & \multicolumn{3}{|c|}{ MNO3 } & \multicolumn{3}{|c|}{ MNO4 } \\
\hline & Morn & After & Even & Morn & After & Even & Morn & After & Even & Morn & After & Even \\
\hline$>-18$ to -14 & 15951 & 14247 & 21144 & 5773 & 5420 & 8695 & 8580 & 7076 & 8580 & 1251 & 1498 & 1238 \\
\hline$>-14$ to -11 & 20414 & 26574 & 24722 & 12797 & 14855 & 11004 & 20253 & 18506 & 20253 & 7118 & 6089 & 3908 \\
\hline$>-11$ to -9 & 7987 & 6731 & 10273 & 10325 & 11143 & 12789 & 10292 & 8614 & 10292 & 9551 & 6310 & 5666 \\
\hline$>-9$ to -7 & 5576 & 4332 & 7184 & 6910 & 6819 & 1116 & 4950 & 4001 & 4950 & 7635 & 8088 & 9399 \\
\hline$>-7$ to 0 & 6422 & 7225 & 9591 & 9579 & 9825 & 14037 & 14648 & 9711 & 14648 & 25469 & 30672 & 37879 \\
\hline $\begin{array}{l}\% \text { EcNo } \\
\text { Samples }>=14 \\
\text { db }\end{array}$ & 71.69 & 75.89 & 71 & 87.29 & 88.72 & 81.74 & 82.29 & 85.23 & 83.38 & 97.54 & 97.15 & 83.38 \\
\hline
\end{tabular}


Table A3: Number of measurements against RSCP range at FUTA area

\begin{tabular}{c|ccc|ccc|ccc|ccc}
\hline & \multicolumn{3}{|c|}{ MNO1 } & \multicolumn{3}{c|}{ MNO2 } & \multicolumn{3}{c}{ MNO3 } & \multicolumn{3}{c}{ MNO4 } \\
\hline RSCP $(\mathrm{dbm})$ & Morn & After & Even & Morn & After & Even & Morn & After & Even & Morn & After & Even \\
\hline$>-110$ to -92 & 36250 & 23302 & 49886 & 3873 & 2993 & 6839 & 3743 & 1591 & 1547 & 9634 & 5027 & 8485 \\
$>$-92 to -85 & 16619 & 6477 & 8742 & 7163 & 5789 & 9357 & 4687 & 3211 & 3963 & 9745 & 7267 & 12511 \\
$>-85$ to -75 & 12150 & 10846 & 8782 & 20083 & 12930 & 21614 & 22731 & 10159 & 16679 & 30233 & 15486 & 19902 \\
$>-75$ to -65 & 17200 & 11634 & 7185 & 27255 & 19498 & 23929 & 30404 & 17070 & 37656 & 22294 & 16374 & 23545 \\
$>-65$ to 0 & 15963 & 10617 & 9724 & 23917 & 16546 & 19194 & 20604 & 18240 & 20601 & 13621 & 9232 & 18013 \\
\hline$\%$ RSCP > = 92dbm & 63.07 & 62.93 & 40.83 & 95.29 & 94.81 & 91.54 & 95.44 & 96.83 & 98.07 & 88.73 & 90.58 & 89.7 \\
\hline
\end{tabular}

Table A4: Number of measurements against EcNo range at FUTA area

\begin{tabular}{|c|c|c|c|c|c|c|c|c|c|c|c|c|}
\hline & \multicolumn{3}{|c|}{ MN01 } & \multicolumn{3}{|c|}{ MNO2 } & \multicolumn{3}{|c|}{ MNO3 } & \multicolumn{3}{|c|}{ MNO4 } \\
\hline & Morn & After & Even & Morn & After & Even & Morn & After & Even & Morn & After & Even \\
\hline$>-18$ to -14 & 2889 & 14347 & 24067 & 15838 & 6285 & 13730 & 7312 & 3618 & 7490 & 296 & 1410 & 440 \\
\hline$>-14$ to -11 & 28731 & 17949 & 24022 & 36059 & 16836 & 3072 & 24236 & 12029 & 28849 & 15715 & 5924 & 7403 \\
\hline$>-11$ to -9 & 15280 & 8045 & 8970 & 14114 & 13217 & 16267 & 29435 & 13629 & 27199 & 10109 & 6743 & 13821 \\
\hline$>-9$ to -7 & 9663 & 5776 & 3609 & 4572 & 8049 & 7299 & 10547 & 8199 & 6779 & 9137 & 7827 & 14694 \\
\hline$>-7$ to 0 & 10337 & 13064 & 10001 & 9849 & 13000 & 11509 & 9786 & 11824 & 9284 & 50970 & 31164 & 46098 \\
\hline $\begin{array}{c}\% \text { EcNo Samples> } \\
=14 \mathrm{db}\end{array}$ & 68.91 & 75.75 & 65.94 & 80.3 & 89.2 & 73.53 & 91 & 92.66 & 90.59 & 99.65 & 97.34 & 99.46 \\
\hline
\end{tabular}

Table A5: Number of measurements against RSCP range at Oja- Arakale area

\begin{tabular}{c|ccc|cccc|cccccc}
\hline & \multicolumn{3}{|c|}{ MNO1 } & \multicolumn{3}{c|}{ MNO2 } & \multicolumn{3}{c}{ MNO3 } & \multicolumn{3}{c}{ MNO4 } \\
\hline RSCP $(\mathrm{dbm})$ & Morn & After & Even & Morn & After & Even & Morn & After & Even & Morn & After & Even \\
\hline$>-110$ to -92 & 13659 & 12376 & 49886 & 0 & 0 & 1729 & 526 & 83 & 1497 & 3080 & 3080 & 6962 \\
$>$-92 to -85 & 12799 & 10237 & 9716 & 333 & 13 & 7195 & 3188 & 1973 & 11936 & 13353 & 13353 & 37346 \\
$>-85$ to -75 & 11166 & 10817 & 27427 & 7610 & 8140 & 36494 & 9709 & 11520 & 41818 & 15119 & 15119 & 42708 \\
$>$ >-75 to -65 & 2813 & 6604 & 38681 & 18896 & 21731 & 49177 & 13010 & 13567 & 36446 & 3775 & 3775 & 20133 \\
$>-65$ to 0 & 3509 & 6574 & 54844 & 12943 & 12268 & 26235 & 13342 & 14104 & 15518 & 4601 & 4601 & 21213 \\
\hline$\%$ RSCP $>=92 \mathrm{dbm}$ & 68.91 & 73.44 & 72.37 & 100 & 100 & 98.56 & 98.67 & 97.76 & 98.72 & 92.28 & 98.95 & 94.57 \\
\hline
\end{tabular}

Table A6: Number of measurements against EcNo range at Oja- Arakale area

\begin{tabular}{c|ccc|ccc|cccccc}
\hline & \multicolumn{3}{|c|}{ MNO1 } & \multicolumn{3}{c|}{ MNO2 } & \multicolumn{3}{c}{ MNO3 } & \multicolumn{3}{c}{ MNO4 } \\
\hline EcNo Sample (db) & Morn & After & Even & Morn & After & Even & Morn & After & Even & Morn & After & Even \\
\hline$>-18$ to -14 & 15086 & 15672 & 46387 & 8170 & 10922 & 27988 & 6974 & 8461 & 25026 & 1066 & 288 & 7858 \\
$>-14$ to -11 & 14376 & 17502 & 50256 & 16110 & 16216 & 38656 & 17983 & 20135 & 59285 & 6449 & 6965 & 43292 \\
$>-11$ to -9 & 3429 & 3147 & 14714 & 8429 & 9432 & 24995 & 7056 & 5558 & 15405 & 8117 & 9176 & 19020 \\
$>-9$ to -7 & 4561 & 3646 & 10889 & 2225 & 684 & 11511 & 2210 & 2289 & 2501 & 9173 & 9811 & 19569 \\
$>-7$ to 0 & 5991 & 6547 & 19927 & 4259 & 4210 & 14736 & 4782 & 4482 & 12302 & 15106 & 15929 & 39193 \\
\hline \% EcNo Samples>=14db & 65.27 & 66.3 & 67.37 & 79.15 & 73.65 & 76.25 & 82.12 & 79.32 & 78.14 & 97.32 & 99.31 & 93.9 \\
\hline
\end{tabular}

A3. KPI measurements

Table A7: KPI measurements for Oja-Arakale area test route

\begin{tabular}{|c|c|c|c|c|c|c|c|c|c|c|c|c|}
\hline \multirow[b]{2}{*}{ Variables } & \multicolumn{4}{|c|}{ Morning } & \multicolumn{4}{|c|}{ Afternoon } & \multicolumn{4}{|c|}{ Evening } \\
\hline & $\begin{array}{l}\mathrm{MN} \\
01\end{array}$ & MNO2 & MNO3 & MNO4 & \begin{tabular}{|c|}
$\mathrm{MN}$ \\
01
\end{tabular} & MNO2 & MNO3 & MNO4 & $\begin{array}{l}\text { MNO } \\
1\end{array}$ & MNO2 & MNO3 & MNO4 \\
\hline Call attempts & 20 & 27 & 26 & 24 & 20 & 27 & 30 & 26 & 64 & 77 & 83 & 79 \\
\hline Call set up & 20 & 27 & 24 & 24 & 20 & 27 & 25 & 26 & 63 & 76 & 69 & 78 \\
\hline Drop calls & 0 & 0 & 0 & 0 & 0 & 0 & 0 & 0 & 0 & 0 & 1 & 0 \\
\hline
\end{tabular}




\begin{tabular}{|c|c|c|c|c|c|c|c|c|c|c|c|c|}
\hline \multirow[b]{2}{*}{ Variables } & \multicolumn{4}{|c|}{ Morning } & \multicolumn{4}{|c|}{ Afternoon } & \multicolumn{4}{|c|}{ Evening } \\
\hline & $\begin{array}{c}\mathrm{MN} \\
01\end{array}$ & MNO2 & MNO3 & MNO4 & \begin{tabular}{|c|}
$\mathrm{MN}$ \\
01
\end{tabular} & MNO2 & MNO3 & MNO4 & $\begin{array}{c}\text { MNO } \\
1\end{array}$ & MNO2 & MNO3 & MNO4 \\
\hline Blocked Calls & 0 & 0 & 2 & 0 & 0 & 0 & 5 & 0 & 1 & 1 & 14 & 1 \\
\hline RRC Established & 8 & 27 & 26 & 30 & 8 & 27 & 30 & 33 & 22 & 80 & 83 & 99 \\
\hline RRC Connection Abnormal Release & 0 & 0 & 0 & 0 & 0 & 0 & 0 & 0 & 4 & 0 & 0 & 0 \\
\hline$\%$ Retainability & 100 & 100 & 100 & 100 & 100 & 100 & 100 & 100 & 100 & 100 & 98.55 & 100 \\
\hline CSSR & 100 & 100 & 92.31 & 100 & 100 & 100 & 83.33 & 100 & 98.44 & 98.7 & 83.13 & 98.13 \\
\hline \% Dropped Calls & 0 & 0 & 0 & 0 & 0 & 0 & 0 & 0 & 0 & 0 & 1.45 & 0 \\
\hline SHO Success Rate & 100 & 100 & 100 & 100 & 100 & 100 & 100 & 100 & 100 & 100 & 100 & 100 \\
\hline RRC Connection & 100 & 100 & 100 & 100 & 100 & 100 & 100 & 100 & 84.62 & 100 & 100 & 100 \\
\hline
\end{tabular}

Table A8: KPI measurements for Alagbaka area test route

\begin{tabular}{|c|c|c|c|c|c|c|c|c|c|c|c|c|}
\hline & \multicolumn{4}{|c|}{ Morning } & \multicolumn{4}{|c|}{ Afternoon } & \multicolumn{4}{|c|}{ Evening } \\
\hline & MN01 & MNO2 & MNO3 & MNO4 & $\begin{array}{l}\text { MNO } \\
1\end{array}$ & MNO2 & MNO3 & MNO4 & $\begin{array}{l}\text { MNO } \\
1\end{array}$ & MNO2 & MNO3 & MNO4 \\
\hline Call attempts & 33 & 40 & 42 & 57 & 28 & 36 & 35 & 33 & 26 & 33 & 28 & 32 \\
\hline Call set up & 32 & 39 & 37 & 33 & 28 & 35 & 31 & 33 & 26 & 33 & 26 & 32 \\
\hline Drop calls & 0 & 1 & 0 & 0 & 0 & 1 & 0 & 0 & 0 & 3 & 0 & 0 \\
\hline Blocked Calls & 1 & 1 & 5 & 24 & 0 & 1 & 4 & 0 & 0 & 0 & 4 & 0 \\
\hline RRC Established & 9 & 45 & 41 & 63 & 14 & 45 & 36 & 35 & 10 & 39 & 28 & 38 \\
\hline $\begin{array}{l}\text { RRC Connection } \\
\text { Abnormal Release }\end{array}$ & 0 & 1 & 0 & 46 & 0 & 3 & 0 & 0 & 0 & 0 & 0 & 0 \\
\hline \% Retainability & 100 & 97.44 & 100 & 100 & 100 & 97.14 & 100 & 100 & 100 & 90.91 & 100 & 100 \\
\hline CSSR & 96.97 & 97.5 & 88.1 & 57.89 & 100 & 97.32 & 88.57 & 100 & 100 & 100 & 92.86 & 100 \\
\hline \% Dropped Calls & 0 & 2.56 & 0 & 0 & 0 & 2.86 & 0 & 0 & 0 & 9.09 & 0 & 0 \\
\hline SHO Success Rate & 100 & 100 & 100 & 100 & 100 & 100 & 100 & 100 & 100 & 100 & 100 & 100 \\
\hline RRC Connection & 100 & 97.83 & 100 & 57.8 & 100 & 93.76 & 100 & 100 & 100 & 100 & 100 & 100 \\
\hline
\end{tabular}

Table A9: KPI measurements for FUTA area test route

\begin{tabular}{|c|c|c|c|c|c|c|c|c|c|c|c|c|}
\hline & \multicolumn{4}{|c|}{ Morning } & \multicolumn{4}{|c|}{ Afternoon } & \multicolumn{4}{|c|}{ Evening } \\
\hline & MN01 & MNO2 & MNO3 & MNO4 & $\begin{array}{l}\text { MNO } \\
1\end{array}$ & MNO2 & MNO3 & MNO4 & $\begin{array}{l}\text { MNO } \\
1\end{array}$ & MNO2 & MNO3 & MNO4 \\
\hline Call attempts & 42 & 47 & 42 & 44 & 43 & 56 & 61 & 55 & 36 & 56 & 55 & 51 \\
\hline Call set up & 15 & 46 & 38 & 44 & 38 & 54 & 52 & 55 & 33 & 54 & 50 & 51 \\
\hline Drop calls & 1 & 0 & 0 & 0 & 0 & 0 & 0 & 0 & 1 & 0 & 0 & 0 \\
\hline Blocked Calls & 27 & 2 & 4 & 4 & 5 & 2 & 9 & 0 & 3 & 2 & 5 & 0 \\
\hline RRC Established & 35 & 47 & 42 & 44 & 24 & 55 & 61 & 75 & 24 & 55 & 58 & 62 \\
\hline $\begin{array}{l}\text { RRC Connection } \\
\text { Abnormal Release }\end{array}$ & 10 & 0 & 0 & 0 & 4 & 0 & 0 & 0 & 7 & 0 & 0 & 0 \\
\hline \% Retainability & 93.33 & 100 & 100 & 100 & 100 & 100 & 100 & 100 & 96.97 & 100 & 100 & 100 \\
\hline CSSR & 35.71 & 97.87 & 90.48 & 100 & 88.37 & 96.43 & 85.25 & 100 & 91.67 & 96.43 & 90.91 & 100 \\
\hline \% Dropped Calls & 6.67 & 0 & 0 & 0 & 0 & 0 & 0 & 0 & 3.03 & 0 & 1.45 & 0 \\
\hline SHO Success Rate & 100 & 100 & 100 & 100 & 100 & 100 & 100 & 100 & 100 & 100 & 100 & 100 \\
\hline RRC Connection & 77.78 & 100 & 100 & 100 & 85.71 & 100 & 100 & 100 & 72.42 & 100 & 100 & 100 \\
\hline
\end{tabular}

